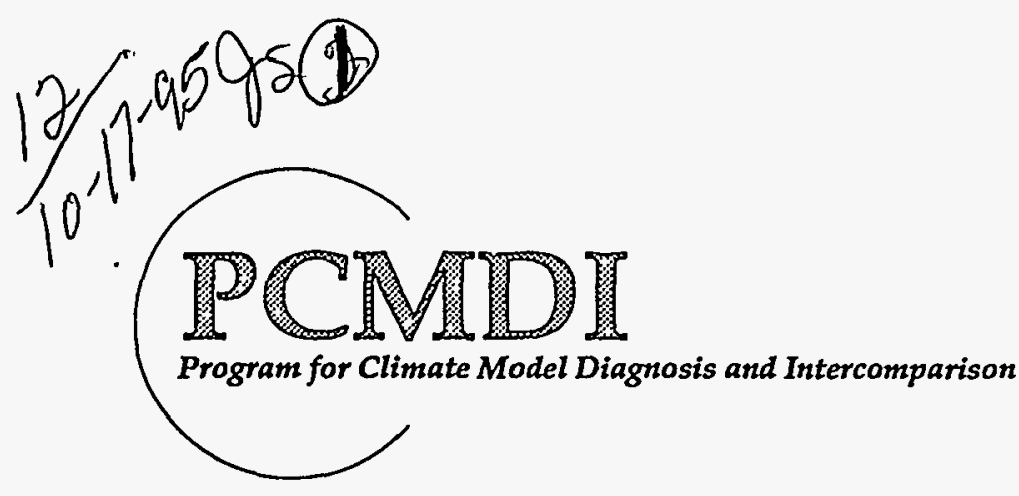

UCRL-ID-121951

RECFIVED

OCT 161995

PCMDI Report No. 26

OSTI

\title{
UNCERTAINTIES IN GLOBAL OCEAN SURFACE HEAT FLUX CLIMATOLOGIES DERIVED FROM SHIP OBSERVATIONS
}

by

Peter J. Gleckler ${ }^{1}$ and Bryan C. Weare ${ }^{2}$

Program for Climate Model Diagnosis and Intercomparison

Lawrence Livermore National Laboratory, Livermore, CA, USA

${ }^{2}$ Department of Land Air and Water Resources

University of California at Davis

Davis, CA, USA

August 1995

PROGRAM FOR CLIMATE MODEL DIAGNOSIS AND INTERCOMPARISON UNIVERSITY OF CALIFORNIA, LAWRENCE LIVERMORE NATIONAL LABORATORY LIVERMORE, CA 94550 


\section{DISCLAMMER}

This document was prepared as an account of work sponsored by an agency of the United States Government. Neither, the United States Government nor the University of California nor any of their employees, makes any warranty, express or implied, or assumes any legal liability or responsibility for the accuracy, completeness, or usefulness of any information, apparatus, product, or process disclosed, or represents that its use would not infringe privately owned rights. Reference herein to any specific commercial products, process, or service by trade name, trademark, manufacturer, or otherwise, does not necessarily constitute or imply its endorsement, recommendation, or favoring by the United States Govemment or the University of California.

The views and opinions of authors expressed herein do not necessarily state or reflect those of the United States Govemment or the University of California, and shall not be used for advertising or product endorsement purposes.

This is an informal report intended primarily for internal or limited external distribution. The opinions and conclusions stated are those of the author and may or may not be those of the Laboratory.

This report has been repoduced directly from the best available copy.

Available to DOE and DOE contractors from the Office of Scientific and Technical Information P.O. Box 62, Oak Ridge, TN 37831

Prices available from (615) 576-8401, FTS 626-8401

Available to the public from the

National Technical Information Service

U.S. Department of Commerce

5285 Port Royal Rd.,

Springfield, VA 22161 


\section{DISCLAIMER}

Portions of this document may be illegible in electronic image products. Images are produced from the best available original document. 


\section{ABSTRACT}

A methodology to define uncertainties associated with ocean surface heat flux calculations has been developed and applied to a revised version of the Oberhuber(1988) global climatology, which utilizes a summary of the COADS surface observations. Systematic and random uncertainties in the net oceanic heat flux and each of its four components at individual grid points and for zonal averages have been estimated for each calendar month and the annual mean. The most important uncertainties of the $2^{\circ} \times 2^{\circ}$ grid cell values of each of the heat fluxes are described. Annual mean net shortwave flux random uncertainties associated with errors in estimating cloud cover in the tropics yield total uncertainties which are greater than $25 \mathrm{~W} \mathrm{~m}^{-2}$. In the northern latitudes, where the large number of observations substantially reduce the influence of these random errors, the systematic uncertainties in the utilized parameterization are largely responsible for total uncertainties in the shortwave fluxes which usually remain greater than $10 \mathrm{~W} \mathrm{~m}^{-2}$. Systematic uncertainties dominate in the zonal means because spatial averaging has led to a further reduction of the random errors. The situation for the annual mean latent heat flux is somewhat different in that even for grid point values the contributions of the systematic uncertainties tend to be larger than those of the random uncertainties at most all latitudes. Latent heat flux uncertainties are greater than $20 \mathrm{~W} \mathrm{~m}^{-2}$ nearly everywhere south of $40^{\circ} \mathrm{N}$, and in excess of $30 \mathrm{~W} \mathrm{~m}^{-2}$ over broad areas of the subtropics, even those with large numbers of observations. Resulting zonal mean latent heat flux uncertainties are largest $\left(\sim 30 \mathrm{~W} \mathrm{~m}^{-}\right.$ $\left.{ }^{2}\right)$ in the middle latitudes and subtropics and smallest $\left(\sim 10-25 \mathrm{~W} \mathrm{~m}^{-2}\right)$ near the equator and over the northernmost regions. Preliminary comparison of zonal average fluxes suggest that most atmospheric general circulation models produce excessively large ocean surface fluxes of net solar heating and evaporative cooling when forced with realistic sea surface temperatures. The method introduced here can be refined to produce increasingly reliable estimates of uncertainties in surface flux atlases derived from ship observations. 


\section{Introduction}

Despite its importance for climate and climate change, the global scale ocean surface energy balance is not well known. Deficiencies in our understanding result from lack of quality observational data and the complex nature of the physical processes involved. Here we focus on quantifying, as best as possible, the uncertainties associated with global ocean surface energy flux climatologies which have been derived from surface observations. Individual sources of error will be examined to identify how they collectively propagate into total uncertainties in the estimates of annual and seasonal mean surface energy fluxes. The reduction of random uncertainties due to averaging techniques will be quantified. In most cases we will not attempt to correct for the more problematic systematic biases in the climatologies, an endeavor which is crucial to enhanced understanding and represents an active area of investigation by many researchers.

An important motivation for this study is to quantify the uncertainties in observationallybased energy flux atlases so that they can be used to evaluate surface energy fluxes simulated by atmosphere and ocean general circulation models. The comparison of model simulated energy fluxes with observationally-based estimates to date has been of limited use because it is well known that there are large uncertainties in the atlases. It has also been known for some time that the present uncertainty in the net oceanic air-sea heat flux substantially exceeds the $10 \mathrm{~W} \mathrm{~m}^{-2}$ required to establish ocean and atmosphere energy budgets to the accuracy required for climate monitoring and prediction (cf. Dobson et al., 1982). Exactly how large these observational uncertainties are remains unclear, but that this is precisely the issue we will address in this study.

Few direct measurements of ocean surface energy fluxes have been made because they are extremely difficult and expensive. To overcome the lack of in situ measurements, parameterizations have been developed to estimate surface energy fluxes from commonly observed fields. Surface air temperature, sea surface temperature, dew point temperature, wind speed and cloud cover are commonly measured or estimated by merchant ships of the volunteer observing fleet and re- 
search vessels. Using the parameterizations in conjunction with data bases containing millions of these observations spanning three or more decades, atlases of monthly mean climatological global ocean surface heat fluxes have been developed (cf. Esbensen and Kushnir, 1981, Hsiung, 1986, and Oberhuber, 1988, and da Silva et al., 1994).

Other observationally-based techniques to estimate large scale surface energy fluxes are used such as operational analyses (c.f. Simonot, and LeTreut, 1987 and Trenberth and Solomon, 1994) and satellite retrieval techniques (Liu, 1988 and Darnell et al., 1992, Chertock et al., 1992 and $\mathrm{Li}$ and et al, 1993). Here we will restrict ourselves to the evaluation of ocean surface energy flux estimates resulting from surface marine observations.

Some studies (cf. Cayan, 1992a) have focused on the interannual variability of ocean surface energy fluxes. Only in the northern oceans (the North Atlantic in particular) is the number of observations available sufficient to study inter-annual variability in any reasonable way. It is our belief that models must have a credible simulation of the seasonal cycle before we can have faith in their ability to realistically capture inter-annual variability, and for this reason we focus on the seasonal mean climatology. In any event, most available estimates are composite climatologies because the observations available in nearly all regions are too scant to provide reasonable estimates for an individual month.

In section 2 the data and parameterizations used in this study are described. In section 3 uncertainties in the observations, the parameterizations, and those due to sampling deficiencies are summarized. The heat flux uncertainty analysis is described in section 4 for each term of the surface energy balance: the net surface shortwave $(S W)$ and longwave $(L W)$ radiation, the latent heat flux $(L H)$, the sensible heat flux $(S H)$ and the net surface heat flux $(N=S W+L W+L H+S H)$. We define all fluxes to be positive downward. In section 5 , the analysis, its potential uses, and its deficiencies are discussed. 


\section{Data}

We utilize a modified version of the Oberhuber atlas (1988) as the basis of our uncertainty estimates. Other atlases (cf. Esbensen and Kushnir, 1981, and Hsiung, 1986, da Silva et al, 1994) could have been used, but we chose that of Oberhuber because it has been used extensively and the raw data required for the analysis which follows are available. It is not clear that the parameterizations used by Oberhuber are superior to other efforts, but for the most part the results of our analysis are not sensitive to the choice of the atlas used, provided certain corrections are made. This is not to suggest that the parameterization used in one atlas is not significantly better than that used in another, but rather that on a global scale, the uncertainties associated with all of them are of comparable magnitude.

To estimate the surface fluxes with the parameterizations which are outlined below, Oberhuber used a monthly climatology (Wright, 1988) of the Comprehensive Ocean-Atmosphere Data Set (COADS, cf. Woodruff et al., 1987). This COADS product was based on data archived from the Voluntary Observing Fleet (VOF) of merchant vessels during the period 1950 to 1979 . The observed fields in the COADS climatology which are needed for the surface flux parameterizations are: surface air temperature $(2 \mathrm{~m}) \mathrm{T}_{\mathrm{a}}$, sea surface temperature $T_{s}$, dew point temperature $(2 \mathrm{~m}) \mathrm{T}_{d}$, surface pressure $P_{s}$, and the more subjective estimates of total cloud cover $C$ and surface wind speed $(10 \mathrm{~m}) \mathrm{V}_{\mathrm{s}}$. To give some sense of the number of observations available, Figure 1 depicts the total number of sea surface temperature observations available during the 30 year period. The distribution of available observations for the other observed fields used in this analysis is similar. There is a steady increase in the total number of observations taken during the 3 decades, but in general those regions with relatively high or low sampling rates remain that way throughout the data collection period.

Oberhuber used the Wright (1988) $2^{\circ}$ latitude by $2^{\circ}$ longitude climatology, and thus the surface flux estimates are made with climatological monthly mean observations. This technique has been frequently referred to as the 'classical' method. A more complex but perhaps preferred technique is to estimate the surface heat fluxes with the 'sampling' method, whereby flux computations 


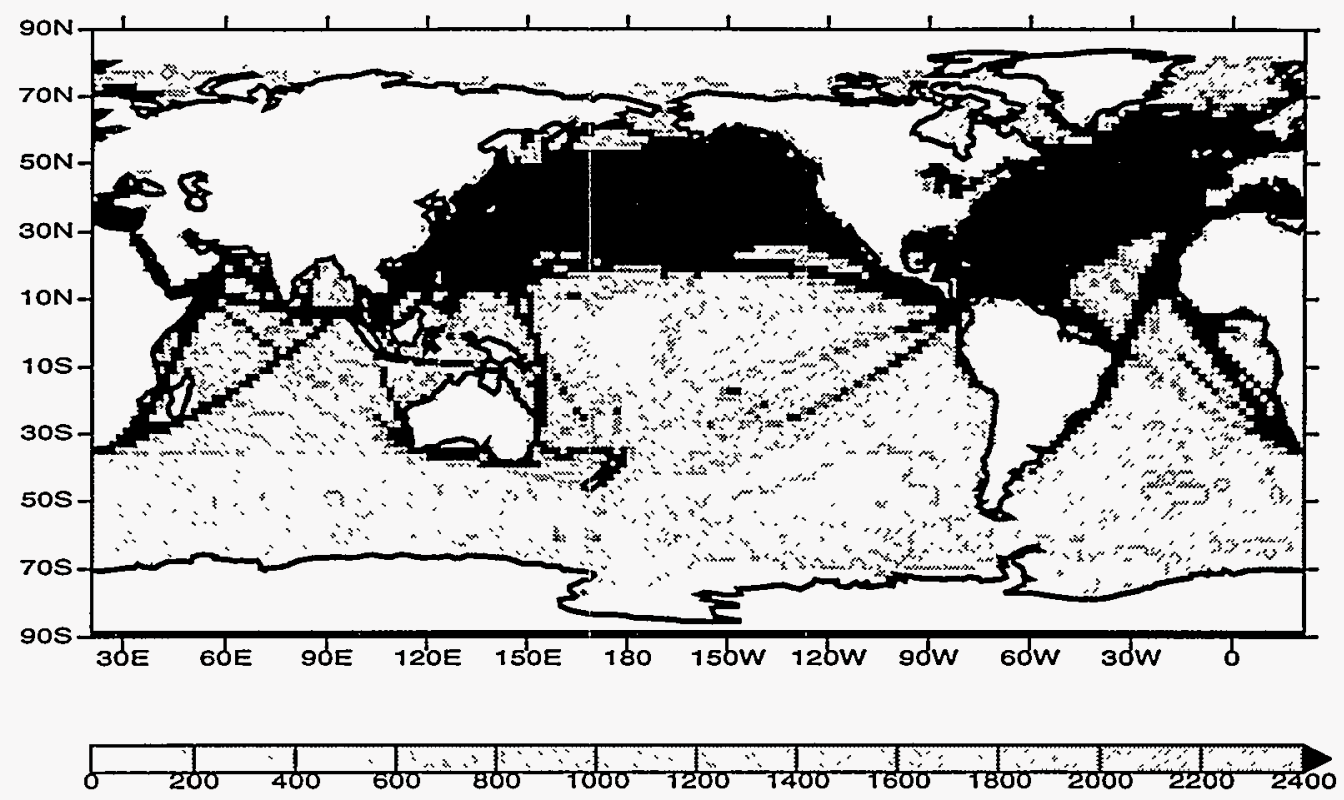

Figure 1: Total number of SST observations in COADS 1950-1979.

are made with individual measurements. We will return to this issue.

For the net shortwave (SW), Oberhuber made use of Reed's (1977) parameterization:

$$
S W=Q_{\delta}[1-\mathrm{A} C+0.0019 Z](1-\alpha)
$$

where $Q_{o}$ is the monthly averaged surface clear sky solar radiation reduced by atmospheric transmissivity (Zillerman, 1972), $\alpha$ is the surface albedo with a constant value of $\alpha=0.06, Z$ is the solar noon altitude in degrees, and $\mathbf{A}$ is a coefficient with a constant value of 0.62 . Oberhuber reduced Reed's $S W$ formulation by $10 \%$ without sound justification in order to adjust the annual mean meridional oceanic heat transport implied from the net surface heat flux, $N$. In the analysis which follows, this reduction of $S W$ is removed because Reed's unaltered $S W$ formula was judged to be the most accurate for monthly mean estimates in an extensive review by Dobson and Smith (1988).

That progress is slow in the large scale estimates of the net longwave flux is evident in the fact that Oberhuber used the parameterization of Berliand (1960) which has been improved little in thrity five years. The Berliand formula is written as:

$$
L W=\varepsilon \sigma T_{s}^{4}\left(0.39-0.05 e_{\mathrm{s}}^{0.5}\right)\left(1-\mathbf{B} C^{2}\right)+4 \varepsilon \sigma T_{a}^{3}\left(T_{s}-T_{a}\right)
$$


where $\mathrm{B}$ is a function of latitude (varying from 1 at the poles to 0.5 at the equator), $e_{\mathrm{s}}$ the air surface vapor pressure (derived from the 'observed dew point temperature), $\varepsilon$ the emissivity of the sea surface, and $\sigma$ the Stefan-Boltzman constant. $T_{a}$ and $T_{s}$ are in units of ${ }^{\circ} \mathrm{K}$.

To date, the only means of making large scale estimates of the turbulent latent (LH) and sensible heat (SH) fluxes requires usage of the classical bulk formulae:

$$
\begin{aligned}
& L H=\rho L C_{E} V_{s}\left(q_{s}-q_{a}\right) \\
& S H=\rho C_{H} V_{s}\left(T_{s}-T_{a}\right)
\end{aligned}
$$

where $q_{a}$ is the surface $(2 \mathrm{~m})$ air specific humidity, and $C_{E}$ and $C_{H}$ are the exchange coefficients for $L H$ and $S H$ respectively. The diagnostic variable $q_{s}$ is defined as the saturation specific humidity at $P_{s}$ and $T_{s}$, while $q_{a}$ is derived from $T_{d}$. Oberhuber has used the empirically-based model of Large and Pond (1982) for $C_{E}$ and $C_{H}$, with some modifications (Oberhuber, 1988).

\section{Measurement, parameterization and sampling uncertainties}

The analysis which follows is an extension of the work of Weare (1989), wherein uncertainties in Weare's (1981) tropical Pacific heat flux atlas were estimated. In this section we summa-

rize estimates of random and systematic uncertainties due to deficiencies in sampling, observing errors, and the parameterizations themselves. Most of these estimates have been cataloged from the work of various researchers involved in the quality control of observations, and by those who are active in parameterization development. In Section 4 we will assess how these uncertainties propagate in the climatological estimates of global ocean surface heat fluxes.

\subsection{Uncertainties in the observed fields}

\section{Random Uncertainties}

To compute surface fluxes with the parameterizations summarized in section 2 requires field observations of $C, \mathrm{~V}_{\mathrm{s}}, \mathrm{T}_{\mathrm{a}}, \mathrm{T}_{\mathrm{s}}, \mathrm{T}_{\mathrm{d}}$ and $\mathrm{P}_{\mathrm{s}}$. Random errors resulting from a single measurement of the directly observed quantities have been estimated (cf. Weare,1989, Taylor, 1984) to be approxi- 
mately $\pm 1{ }^{\circ} \mathrm{C}$ for $T_{a}, T_{s}$ and $T_{d}$. These estimates are meant to represent any random error in the reading of the thermometer, or a bias in any given instrument. A bias in a single thermometer will be considered a random error in the total data set because many different thermometers were used to measure temperature within a given $2^{\circ} \times 2^{\circ}$ grid cell during the 30 year period.

The random uncertainty associated with the estimated (as opposed to measured) quantities of $\mathrm{V}_{\mathrm{s}}$ and $C$ are more elusive. Estimated reports of $\mathrm{V}_{\mathrm{s}}$ in COADS are based on the official Beaufort equivalent scale of the World Meteorological Organization (WMO), code 1100 (WMO, 1970). Using the Beaufort scale, visual estimates of the sea state are converted to wind speed using a conversion table. The situation is complicated by the fact that the fraction of reported observations measured with anemometers has been steadily increasing (cf. Taylor et al., 1994). Unfortunately there is no distinction between estimated and measured reports in the COADS monthly summaries (Woodruff et al., 1987), but for most locations and years the number of anemometer wind measurements has been less than $20 \%$ of all reports. A multitude of random errors can arise in an estimate of surface wind speed. For example, the Beaufort scale is based on the sea state which is dependent on the magnitude, duration and areal coverage of the wind. To get a sense of a typical random error in an estimate of $\mathrm{V}_{\mathrm{s}}$, we have examined the standard deviation of observations made within a given month, a product available in the COADS (1950-1979) data set. We calculate an 'average' standard deviation $(\overline{\mathrm{S}})$ for each calendar month $\mathrm{k}$ :

$$
S\left(V_{s}(i, j, k)\right)=\frac{1}{N} \sum_{t} S\left(V_{s}(i, j, k, t)\right)
$$

where $N$ is the total number of years (t) with at least 10 observations for a given longitude (i) - latitude $(j) 2^{\circ} \times 2^{\circ}$ cell. For example, our January calculation was based on the up to 30 sample standard deviations $(S)$ available for each January between 1950 and 1979. Note that by assuming this averaged standard deviation is related to random uncertainties in measurements, we may be overestimating the random uncertainties since at least part of the standard deviation is a measure of actual variability. 
As shown in Figure 2a, in the North Atlantic the standard deviation (normalized by the climatological $\mathrm{V}_{\mathrm{s}}$ ) was found to be larger than elsewhere, presumably representing higher meteorological variability. We have assumed that outside the North Atlantic the variability which exists is predominantly due to random errors (which again yields a conservative estimate of the uncertainty). With this measure, we rather subjectively estimated the random error for a single estimate of $\mathrm{V}_{\mathrm{s}}$ to be $50 \%$.
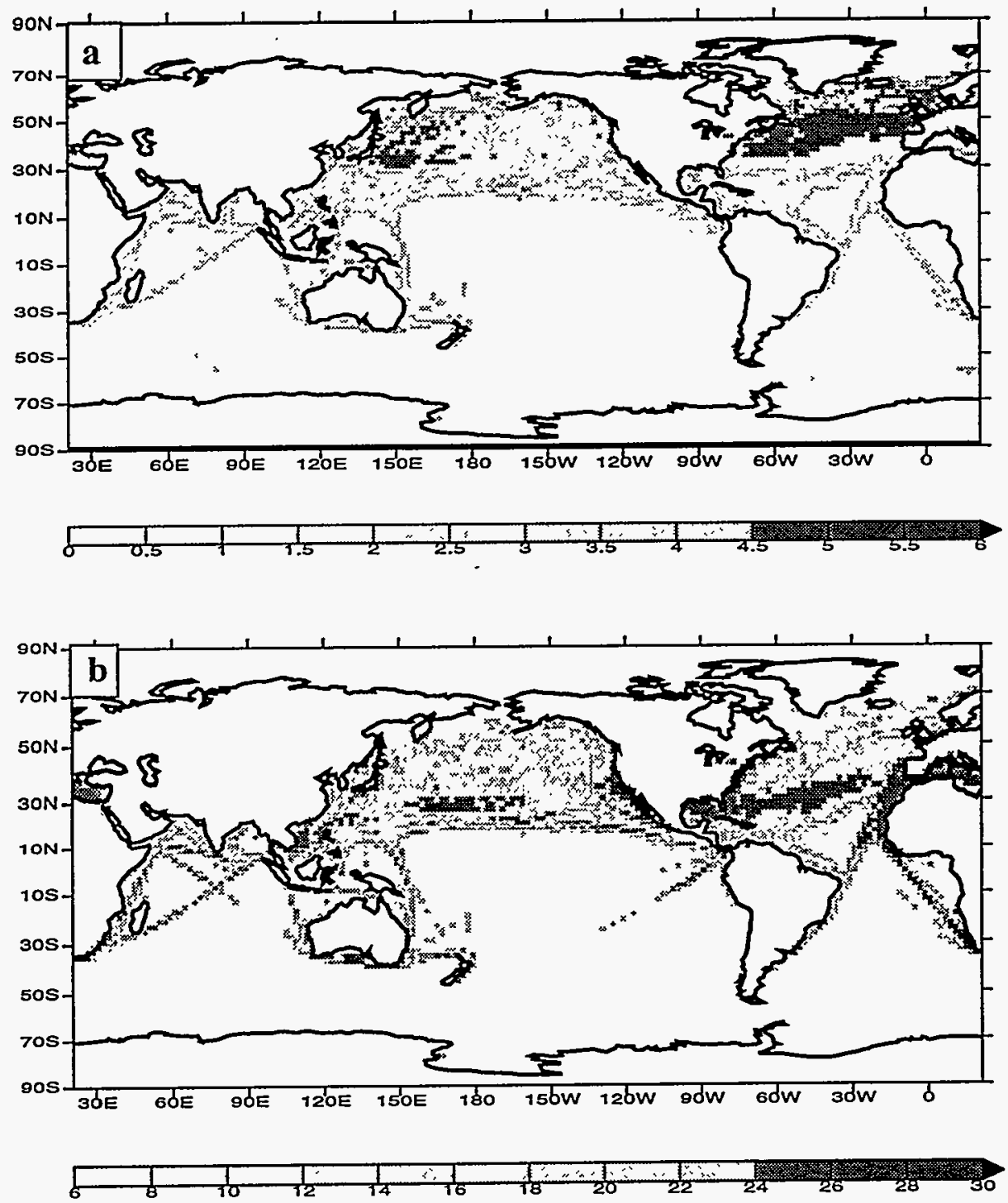

Figure 2: Average monthly standard deviation of all Januarys between 1950-1979 which have greater than 10 observations per month for: a) surface wind (normalized by climatological $\mathrm{V}_{\mathrm{s}}$ ) $(\%)$ and b) cloud cover (\%). 
The estimates of $C$ are reported in eights, ranging from clear skies (0/8) to overcast (8/8). Such estimates made by the VOF are extremely subjective. We have evaluated the year-to-year variability of $C$ in the same manner as we did $V_{s}$ in order to make a judgement on the random errors associated with such cloud cover estimates (Figure 2b). In many areas the variability is roughly $20-$ $25 \%$. We again chose to be conservative by assuming that this variability is predominantly due to random uncertainties in measurements, and not actual variability. It is probable however that the uncertainty is a function of cloud cover itself. For clear and overcast skies, the random uncertainty in a given estimate is likely to be much less than for partly cloudy skies. Our estimate of the random error for a single estimate of $C$ is $2 / 8(25 \%)$ for all conditions.

\section{Systematic Uncertainties}

The assessment of systematic errors in ship-based observations is perhaps more difficult than the case of random errors. Systematic errors of $\mathrm{T}_{\mathrm{s}}$ are probably best understood. Measurements of $T_{s}$ are usually made by sampling engine-intake water, which was found to be systematically too warm by Saur (1963) by roughly $0.7^{\circ} \mathrm{C}$. Subsequent investigators have found this discrepancy is a strong function of location and season and that other factors are also important. Before the use of engine-intake sea water was commonly used for measurement, both insulated and uninsulated buckets were employed. In any case, it is difficult to make a rigorous estimate of these errors, because the frequency of use of the three methods (engine-intake, buckets insulated and not insulated) is not known. Jones et al. (1991) have suggested that since 1950 discrepancies have been greatly reduced. An estimate of $\pm 0.5^{\circ} \mathrm{C}$ will be used here for the systematic uncertainty in $T_{\mathrm{s}}$.

It has become evident that systematic errors might also be present in $\mathrm{T}_{\mathrm{a}}$ measurements (Weber, 1985). Shifts in decadal means of $\mathrm{T}_{\mathrm{a}}$ have been observed, which seem to be related to changes in the method of measurement. Kent et al. (1993) have attempted to correct biases from instrument exposure to sunlight and wind. Other factors may also contribute to error, such as the "heat island" effect of a ship's hull. Despite progress in identifying sources of systematic errors, biases of either 
sign are possible, and they are likely to vary with circumstance. We will assume that the systematic uncertainty of $\mathrm{T}_{\mathrm{a}}$ is also approximately $\pm 0.5^{\circ} \mathrm{C}$.

It has often been suggested that the systematic uncertainty in the $T_{d}$ measurements is negligible because it is typically measured with a sling psychrometer which should be well-ventilated. Isemer et al. (1989) have assumed the systematic uncertainty in $T_{a}-T_{d}$ to be only $0.2^{\circ} \mathrm{C}$. However, Kent et al. (1993) have shown that systematic errors in $T_{d}$ can arise from inadequate ventilation or a contaminated or imperfectly wetted wick. Each contribute to a decreased wet-bulb depression and consequentially an increased dewpoint temperature. The situation is more complicated as there are several methods which are routinely used to measure dew point, and without knowing which observations were made with which type of instrument it is difficult to identify the relative importance of possible biases on the climatologies. We suspect that the error estimate of Isemer et al. (1989) is too small and we will use $0.25^{\circ} \mathrm{C}$ as the systematic uncertainty in $T_{d}$.

Sea surface $(10 \mathrm{~m})$ wind measurements are either derived from Beaufort estimates of the sea state or by direct anemometer measurement. There is no distinction in the COADS monthly summary between estimated and measured reports, and it is thus difficult to determine the relative importance of the errors resulting from the two methods. However, we do know that most of the data in the Wright (1988) climatology used by Oberhuber consists of estimated wind speeds (before 1970 there were few ship equipped with anemometers) and thus we have assumed that the majority of the records are estimated winds. Based on Atlantic Ocean observations, Isemer and Hasse (1991) have suggested that there is a systematic underestimate of Beaufort surface wind speeds on the order of $1.5 \mathrm{~m} \mathrm{~s}^{-1}$. Although Isemer and Hasse claim to have determined the sign of the bias, we make no attempt to correct the Oberhuber atlas, but we do use their correction as an estimate of the systematic error in the surface wind speed.

Fractional cloudiness estimates made by surface observers are fraught with uncertainty (Warren, 1988). However, systematic errors in observed quantities contribute to surface heat fluxes uncertainties only if the observed quantities or the averaging methods used in applying the obser- 
vations to the parameterizations differ from the data or the averaging methods originally used to derive the parameterizations. For example, suppose a systematic bias does exist in the estimates of C. The SW and LW radiation formulae (Eqs. 1 and 2) were derived by fitting a wide range of these biased observations to relatively accurate direct (radiometer) measurements of the fluxes. Presumably the resulting parameterizations thus yield reasonable estimates provided they are made with the biased data. Because all of the data which is used is estimated in a similar fashion, we assume that the systematic uncertainty in $C$ which affects the radiation flux parameterizations is negligible. This is not to suggest that a significant systematic uncertainty in $C$ does not exist.

Oberhuber chose to use a constant albedo $(\alpha=0.06)$ in his use of the Reed parameterization. Payne (1972) found that the monthly mean $\alpha$ seldom departs from 0.06 by more than 0.01 equatorward of $60^{\circ}$ in the Atlantic. We have used 0.01 for our estimate of the systematic uncertainty in the albedo. When sea ice is present this is clearly not appropriate, but in this study we can adequately analyze only those areas of the ocean which are free of ice.

Table 1

Uncertainty estimates of observed fields which contribute to flux uncertainties

\begin{tabular}{|l||c||c|}
\hline \multicolumn{1}{|c||}{ Observed Field } & Random & Systematic \\
\hline Surface air temperature, $\mathrm{T}_{\mathrm{a}}$ & $1^{\circ} \mathrm{C}$ & $0.5^{\circ} \mathrm{C}$ \\
\hline Sea surface temperature, $\mathrm{T}_{\mathrm{s}}$ & $1^{\circ} \mathrm{C}$ & $0.5^{\circ} \mathrm{C}$ \\
\hline Surface Dew pt. temperature, $\mathrm{T}_{\mathrm{d}}$ & $1^{\circ} \mathrm{C}$ & $0.25^{\circ} \mathrm{C}$ \\
\hline Surface wind speed, $\mathrm{V}_{\mathrm{s}}$ & $.50 \cdot \mathrm{V}_{\mathrm{s}}$ & $1.5 \mathrm{~m} / \mathrm{s}$ \\
\hline Total cloud cover, $\mathrm{C}$ & $2 / 8$ & - \\
\hline Surface $\mathrm{SW}$ albedo, $\alpha$ & $.01 \cdot \mathrm{SW}$ & $.01 \cdot \mathrm{SW}$ \\
\hline$\varepsilon(\mathrm{LW})$ & - & $5 \mathrm{~W} / \mathrm{m}^{2}$ \\
\hline
\end{tabular}

The uncertainty estimates summarized here are listed in Table 1 . We will use these to examine how uncertainties collectively propagate in the estimate of surface heat fluxes. Although the list may not be complete, we feel it is a reasonable representation of the dominate uncertainties in the observed quantities. Note the uncertainty estimates listed in Table 1 are meant to represent the 
uncertainties in the observed quantities which contribute to the uncertainties in the surface heat fluxes. As pointed out earlier there may very well be substantial systematic biases in the estimates of $C$, but these are in effect built into the parameterization and thus are not included in Table 1.

\subsection{Parameterization and direct measurement flux uncertainties}

Random and systematic errors in surface heat fluxes can result even if there are no errors in the observed quantities of the VOF. This is because the development of the parameterizations relies on relatively few high quality but imperfect direct observations which have sampled a nearly limitless combinations of possible states in nature. When possible, we divide these uncertainties into those due to the instrumentation used to make direct observations and those due to errors in the parameterizations.

Systematic uncertainties in direct measurements (made before or specifically for the development of the parameterizations) of radiative fluxes have been estimated by Simpson and Paulson (1979) to be approximately $\pm 5 \%$. Included in their estimates were problems due to the effects of ship motion, shadowing effects of ship hulls, and radiometer calibration. More recently Frohlich and London (1986) suggest that the error in the SW marine measurements can be reduced to 1-2\%. Hourly measurements taken for six years aboard the Oceanographer were used for an extensive validation of the Reed parameterization (Reed, 1982). The pyranometers aboard the Oceanographer were carefully calibrated, and that the systematic errors in the SW measurements probably did not exceed $2 \%$. We will use $2 \%$ as our choice of the SW instrumentation uncertainty. Direct measurements of LW are more difficult and less frequent, and thus we have decided to use the higher estimate of $5 \%$ made by Simpson and Paulson.

Dobson and Smith (1988) compared the various SW formulae with direct observations made on ships and several open ocean islands. They found that for climatological estimates, the Reed model was in closest agreement with observations. Parameterizations which were designed to account for cloud type information (such as low, middle and high) appeared to have little advantage, although this conclusion may not apply for parameterizations based on and used for estimates of 
SW over land (c.f., Davies et al., 1985). With a large number of observations, Dobson and Smith (1988) found the Reed formula yielded estimates which differed systematically from the direct measurements by no more than $8 \mathrm{~W} \mathrm{~m}^{-2}$ at three separate ocean weather stations $\left(59^{\circ} \mathrm{N}-19^{\circ} \mathrm{W}\right.$, $52^{\circ} \mathrm{N}-20^{\circ} \mathrm{W}$ and $44^{\circ} \mathrm{N}-60^{\circ} \mathrm{W}$ ), where hourly measurements are available for 15,14 and 12 years respectively. Reed (1982) tested the his parameterization by utilizing data from the Oceanographer, which traversed through many meteorologically varying regions from $7^{\circ} \mathrm{S}$ to $66^{\circ} \mathrm{N}$ in the $\mathrm{Pa}$ cific Ocean. Six years of hourly visual estimates of $C$ are available from this extended cruise, along with hourly accumulations from radiometers. Making use of the data from this extended expedition, the Reed parameterization was found to have a standard error (based on one standard deviation) of approximately $6.5 \%$ (Reed, 1982). As a wide range of conditions were surveyed with what is likely to be reasonable sampling and duration (hourly, for multiple years), we have chosen to use this value $(6.5 \%)$ to represent the systematic uncertainty of the Reed parameterization. We assume the dominant random uncertainty is due to the estimate of $C$, not the parameterization itself.

Uncertainties associated with LW parameterizations have been examined by Simpson and Paulson (1979) and Fung et al. (1984). Both studies emphasize that uncertainty estimates themselves are limited by the lack of direct measurements over the open ocean, of which there are far fewer than for the SW. The results of Simpson and Paulson suggest that under cloudy conditions there is a random error of roughly $5 \mathrm{~W} \mathrm{~m}^{-2}$ associated with the Berliand formula. (Note this differs from the case of random uncertainties associated with the SW parameterization, which were considered negligible because it is based on many more observations). Fung et al. (1984) estimated the systematic uncertainty of the Berliand formula to be $5 \mathrm{~W} \mathrm{~m}^{-2}$ under all conditions. We will use the estimates of Simpson and Paulson (1979) and Fung (1984) for our measures of the random and systematic uncertainties in Oberhuber's use of the Berliand formula, but it must be emphasized that these uncertainties are particularly subjective because there are so few direct measurements available for validation. 
Blanc (1987) compared a variety SH and LH exchange coefficients with 'direct' measurements (eddy correlation and dissipation techniques) and suggested that the systematic uncertainty associated with both coefficients is on average about $12 \%$, which apparently includes the uncertainty in the direct measurements. In another study (Anderson and Smith, 1981) it was found that the majority of methods used to model the exchange coefficients yield random uncertainties of about $20 \%$. It is generally believed that these estimates are reasonable for winds between 2 and $11 \mathrm{~m} \mathrm{~s}^{-1}$, but that outside this range the random uncertainties are likely to be higher. The estimate of random and systematic uncertainties made by Blanc (1987) and Anderson and Smith (1981) will be used here. It is worth noting that many investigators (e.g. Kent et.al, 1993, Isemer and Hasse, 1991) have demonstrated that the exchange coefficients used in the global atlases of Esbensen and Kushnir (1981), Hsiung (1986) and Oberhuber (1988) were unjustifiably large given the estimates based on eddy-correlation techniques. Presumably these higher values were chosen to match insitu experiments and possibly compensating for systematic underestimates in the winds derived from the Beaufort scale (Isemer and Hasse, 1991).

Table 2

Uncertainty estimates associated with bulk parameterizations

\begin{tabular}{|l|c|c|}
\hline \hline & Random & Systematic \\
\hline \hline Instrumentation, $\mathrm{SW}_{\mathrm{I}}$ & - & $0.02 \cdot \mathrm{SW}$ \\
\hline $\mathrm{LW}$ Instrumentation, $\mathrm{LW}_{\mathrm{I}}$ & - & $0.05 \cdot \mathrm{LW}$ \\
\hline Parameterization, $\mathrm{SW}_{\mathrm{P}}$ & - & $.065 \cdot \mathrm{SW}$ \\
\hline Parameterization, $\mathrm{LW}_{\mathrm{P}}$ & $5 \mathrm{~W} / \mathrm{m}^{2}$ & $0.05 \cdot \mathrm{LW}$ \\
\hline$C_{\mathrm{E}}, C_{\mathrm{H}}(\mathrm{LH}, \mathrm{SH})$ & $0.20 \cdot(\mathrm{LH}, \mathrm{SH})$ & $0.12 \cdot(\mathrm{LH}, \mathrm{SH})$ \\
\hline
\end{tabular}

Uncertainty estimates associated with the surface flux parameterizations are summarized in Table 2. For the radiation fields no attempt is made to partition the uncertainties into the various terms in each formula, and all of the parameterization uncertainties of the $\mathrm{LH}$ and SH are attributed to the turbulent exchange coefficients. 


\subsection{Uncertainties due to sampling deficiencies}

How many observations are required to make a reasonable estimate of a climatological monthly mean flux field? For the case of normally distributed random errors, the overall uncertainty is reduced by $\mathrm{N}^{-1 / 2}$, where $\mathrm{N}$ is the total number of observations. Several investigators (cf. Cayan, 1992b and Weare, 1992) have demonstrated at a number of locations in the tropics and midlatitudes that given a sufficient sample size, it is reasonable to assume that the year-to-year variability is normally distributed. Thus for most circumstances simple sampling theory is applicable and will be used here. However, sampling errors which are not random can arise in a number of circumstances.

A spatial sampling bias could result if merchant ships routinely sampled one area of a grid cell more than other areas. These might be important in coastal areas and especially along sharp gradients such as those exhibited by the western boundary currents. The possibility of such a bias was considered by Weare (1981), and found to be much less importance than those due to parameterization or measurement uncertainties, especially in the open ocean. Moreover, any spatial bias here is thought to be much smaller than in Weare's (1981) study because the observations used by Oberhuber have been accumulated in $2^{\circ} \times 2^{\circ}$ grid cells rather than $5^{\circ} \times 5^{\circ}$. Gulev (1994) has carefully analyzed spatial biases in the North Atlantic, and has subsequently developed parameterization corrections. Although such modifications to the parameterizations are likely to be important for studies of variability, their influence is small compared to the dominant uncertainties which we consider here.

Oberhuber's SW estimate was made with a monthly mean COADS product which includes some nighttime observations. This could lead to a possible bias in the flux estimates, particularly in areas of marine stratus where the diurnal variability can be important. Hahn et al. (1995) have attempted to quantify this bias which apparently is largest in the Arctic winter and can reach as much as $8 \%$. We will not account for this bias because it can easily be removed by using daytime only cloud cover atlases such as that developed by Hahn et al. (1995), and here our interest lies in 
those uncertainties for which there is no immediate solution. Day/night biases may also exist for $\mathrm{LH}$ and SH due to variations in the winds and air-sea gradients of moisture and temperature, but we believe these are much smaller than other uncertainties considered here.

Another possible problem may result form what has become commonly know as a "fair weather" bias. Kent and Taylor (1995) noted fewer observations have been taken at high latitude during the winter months. However, they suggest that this does not necessarily result in a bias if the observations available are randomly distributed with respect to weather conditions. Testing this possibility, they concluded that there does not appear to be significant rerouting of ships during periods of high winds, at least with regards to the ocean weather station they used as a reference $\left(57^{\circ} \mathrm{N} 20^{\circ} \mathrm{W}\right)$. It is important to note that such biases can occur, particularly in high latitudes, but we will make no attempt to quantify them here

With the sampling method, individual flux estimates are determined from ship reports and are subsequently averaged over the period of sampling. With the classical technique, meteorological variables are averaged first and flux computations with these averaged quantities (e.g., . with the classical method $\left.\overline{\mathrm{LH}}=\mathrm{LH}\left(\bar{V}_{\mathrm{s}}, \bar{T}_{\mathrm{s}}, \bar{T}_{\mathrm{d}}\right)\right)$. Oberhuber and most others have made use of the classical method because it greatly simplifies the amount of work and generally is regarded to be a reasonable approximation of the sampling method. Many studies (Esbensen et al., 1981b, Hanwana 1987, and Simpson et al., 1979, Simmonds and Dix, 1989) suggest that this is a reasonable approximation but does lead to minor discrepancies when comparisons are made with the more correct approach of computing the fluxes before averaging. Josey et al. (1994) found that the monthly LH flux estimated with the classical method overestimates the sampling method by a few $\mathrm{W} \mathrm{m}^{-2}$ in summer and roughly $7 \mathrm{~W} \mathrm{~m}^{-2}$ in winter. While these biases are not negligible, we will see that they are small compared to several other LH uncertainties. In any case, the importance of the method used is not agreed on by all investigators (c.f., Gulev, 1994). For the SH Josey et al. found the differences between the two methods to be on the order of $1 \mathrm{~W} \mathrm{~m}^{-2}$, and consequently much smaller than the inter-annual variation estimate of the North Atlantic (Cayan, 1992a). This is in contrast to 
the study of Fissel et al.(1979), who found the biases in SH owing to the classical method to be important and that accurate measurements require a sampling interval of 48 hours. On the other hand, an important result of the Fissel et al. study (1979) is that extreme weather events did little to alter the climatological estimates of the $\mathrm{LH}$ and SH fluxes. Clearly further studies are needed, and preferably at a variety of locations to fully justify or refute the classical method of computing surface fluxes with VOF data.

\section{Ocean surface heat flux uncertainties}

To estimate how the uncertainties summarized in Section 3 propagate into uncertainties in the surface heat fluxes, we make use of basic sampling theory (Taylor, 1982) which is briefly summarized here. Consider the special case of a variable $F$, which is a function of two variables $x$ and $y$. The uncertainty estimate, $\sigma_{F}$, for a single measurement of $x$ and $y$ is:

$$
\sigma_{F}=\sqrt{\left(\frac{\partial F}{\partial x}\right)^{2} \sigma_{x}^{2}+\left(\frac{\partial F}{\partial y}\right)^{2} \sigma_{y}^{2}+2 \rho_{x y}\left(\frac{\partial F}{\partial x} \frac{\partial F}{\partial y}\right) \sigma_{x} \sigma_{y}}
$$

where $\sigma_{x}$ and $\sigma_{y}$ are the random and systematic uncertainties in $x$ and $y$, and $\rho_{x y}$ is the correlation between $x$ and $y$. If $x$ and $y$ are independent, they will not be correlated and thus the third term in Eq. (6) will vanish. If they are fully dependent $\left(\rho_{x y}=1\right)$, then Eq.(6) yields the maximum possible propagation of the uncertainties. In cases where where $\mathrm{x}$ and $\mathrm{y}$ are anticorrelated $\left(\rho_{\mathrm{xy}}<1\right)$ then the third term in Eq (6) can act to reduce $\sigma_{\mathrm{F}}$.

If we are estimating uncertainties from a collection of measurements of each observable (as opposed to Eq. (6) which is based on only a single measurement of $\mathrm{x}$ ), then for instance the first term on the right hand side of Eq. (6) may be expanded to:

$$
\left(\frac{\partial F}{\partial x}\right)^{2} \sigma_{x}^{2} \Rightarrow\left(\frac{\partial F}{\partial x}\right)^{2} \sigma_{x, s y s}^{2}+\left(\frac{\partial F}{\partial x}\right)^{2} \sigma_{x, \text { ran }}^{2} f(N)
$$

where $\sigma_{x, \text { sys }}$ and $\sigma_{x, \text { ran }}$ are estimates of the systematic and random uncertainties of $x$ respectively. Random uncertainties will be reduced by $f(\mathrm{~N})=\mathrm{N}^{-1 / 2}$ because we have already pointed out that 
studies suggest that simple sampling theory is reasonable for our analysis. We will generalize the methodology outlined here to account for more than two variables.

\subsection{Surface net shortwave radiation}

The uncertainty resulting from Oberhuber's use of the Reed SW parameterization (which we have corrected by increasing by $10 \%$ as described in Section 2) may be formulated using Eqs. (6) and (7). Using the uncertainties listed in Tables 1 and 2 the total uncertainty in the SW is:

$$
\sigma_{S W}=\sqrt{\sigma_{S W_{I, s y s}}^{2}+\sigma_{S W_{P, s y s}}^{2}+\left(\frac{\partial}{\partial C} S W \cdot \sigma_{C, \text { ran }} \cdot f(N)\right)^{2}+\sigma_{\alpha, s y s}^{2}+\left(\sigma_{\alpha, \text { ran }} \cdot f(N)\right)^{2}}
$$

Only the third term in Eq. (8) has a partial differentiation (as in Eq. 6) because all the other uncertainties in Tables 1 and 2 are estimated as percentage uncertainties of the SW. We have assumed here that all possible correlation terms are zero because each term in Eq. 8 represents an indepen-. dent source of error. The random uncertainty reduction factor is $f(N)=\mathrm{N}^{-1 / 2}$, where $\mathrm{N}$ is the total number of observations within a given grid cell for a particular climatological month.

In order to properly account for seasonal variations in the uncertainties, the climatological monthly mean uncertainties are first computed. Estimates of the climatological annual and seasonal means are then derived from the root-mean-square of the monthly mean estimates. This procedure is used to estimate the uncertainties for each component of the surface energy balance.

Uncertainties in the climatological annual mean net SW are shown in Fig. 3. Grey areas over the oceans indicate that for at least one climatological month there were fewer than 10 observations of total cloud cover available for the entire 30 year period. Figure $3 a$ shows the SW systematic uncertainties (instrumentation and parameterization), which are quite homogenous spatially and range from approximately $5-10 \mathrm{~W} \mathrm{~m}^{-2}$ in the northern oceans to $15-20 \mathrm{~W} \mathrm{~m}^{-2}$ in the tropics. The random uncertainties associated with $C$ (Fig. 3b) are between 5 to $10 \mathrm{~W} \mathrm{~m}^{-2}$ in the northern oceans, and greater than $25 \mathrm{~W} \mathrm{~m}^{-2}$ in the tropics and southern oceans except along common routes for merchant ships where there are many more observations. 

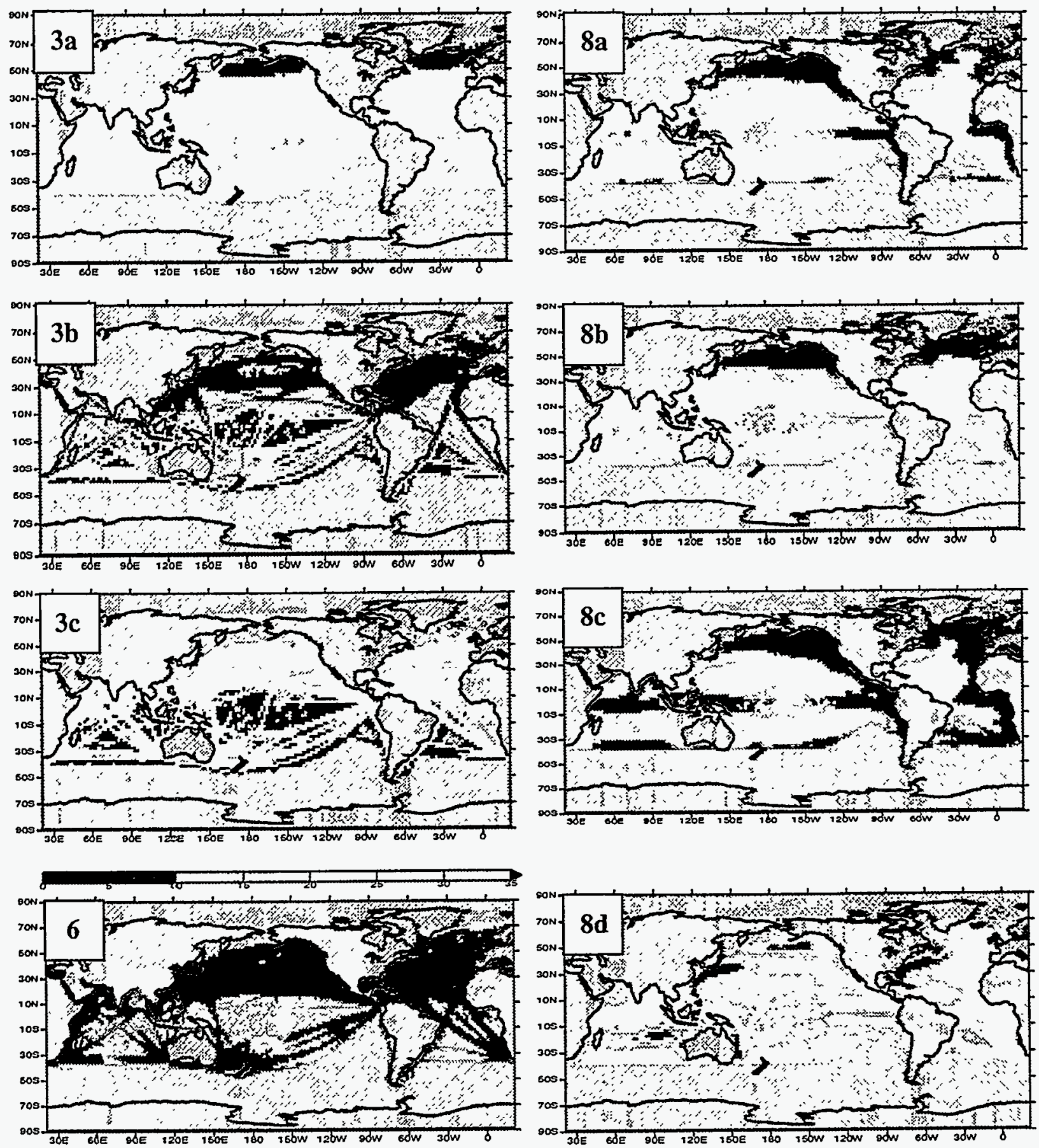

Figure 3: Annual mean net surface shortwave uncertainties $\left(\mathrm{W} \mathrm{m}^{-2}\right)$ : a) systematic $\left.\mathrm{b}\right)$ random and c) total.

Figure 6: Annual mean net surface longwave total uncertainties $\left(\mathrm{W} \mathrm{m}^{-2}\right)$.

Figure 8: Annual mean latent heat uncertainties $\left(\mathrm{W} \mathrm{m}^{-2}\right)$ : a) exchange coefficient (systematic)

b) surface wind speed (systematic) c) moisture gradient (systematic) d) total. 
The total uncertainties in the annual mean SW shown in Fig $3 \mathrm{c}$ are between $10-20 \mathrm{~W} \mathrm{~m}^{-2}$ in the northern oceans, with slightly more contribution resulting from the systematic uncertainty. In the tropics and southern oceans the random uncertainties dominate.

This assessment of uncertainties demonstrates the relative importance of the various sources of error and how they vary spatially. However, it is desirable to reduce this information into a more compact form. The most obvious measure is to examine the zonal means of the uncertainties, which would be a useful first step in the validation of surface heat fluxes simulated by climate mod els. The random uncertainties can be reduced by spatial averaging in a manner analogous to what we have done with the uncertainties at each $2^{\circ} \times 2^{\circ}$ grid cell. For instance, if there are $\mathrm{M}$ grid boxes along a line of latitude, we can estimate random uncertainty in the zonally averaged SW by:

$$
\sigma_{[S W], \text { ran }}=\left[\sigma_{S W, \text { ran }}\right] \cdot g(M)
$$

where the square brackets denote a zonal average and $g(M)$ is the function representing the reduction of random errors when averaging spatially. If the random uncertainties associated with each grid box are independent of one another, then $g(M)=M^{-1 / 2}$. However, an assumption of spatial independence is probably not reasonable for some variables such as $C$. An observer may estimate clear-sky or overcast conditions quite well, but partly cloudy conditions with much more uncertainty. We cannot directly estimate how $\sigma_{C \text {,ran }}$ varies spatially, but we do know how $C$ varies. To estimate the possible impact of the spatial dependance of $\sigma_{C \text {,ran }}$ we therefore compute the spatial lag correlations of $C$ and presume that they are similar to those of $\sigma_{C \text {,ran }}$. The lag correlation enables us to estimate the number of degrees of freedom and hence an appropriate value of $g(M)$. Figure 4a shows the spatial lag correlations for the departures from the zonally averaged January monthly mean climatology of $C$ at each latitude in the Pacific Ocean. The maximum correlation is clearly in the tropics. We have chosen to use as a length scale of dependence the number of grid cells at which the lag correlation drops to $L_{\text {cuttoff }}=0.4$. For example, at $30^{\circ} \mathrm{N}$ the lag correlation of the departure from the zonal average of $C$ is 0.4 after 7 grid cells, and thus $g(M)=(M / 7)^{-1 / 2}$. Tests demonstrated that our results are not very sensitive to $L_{\text {cuttoff- }}$ 

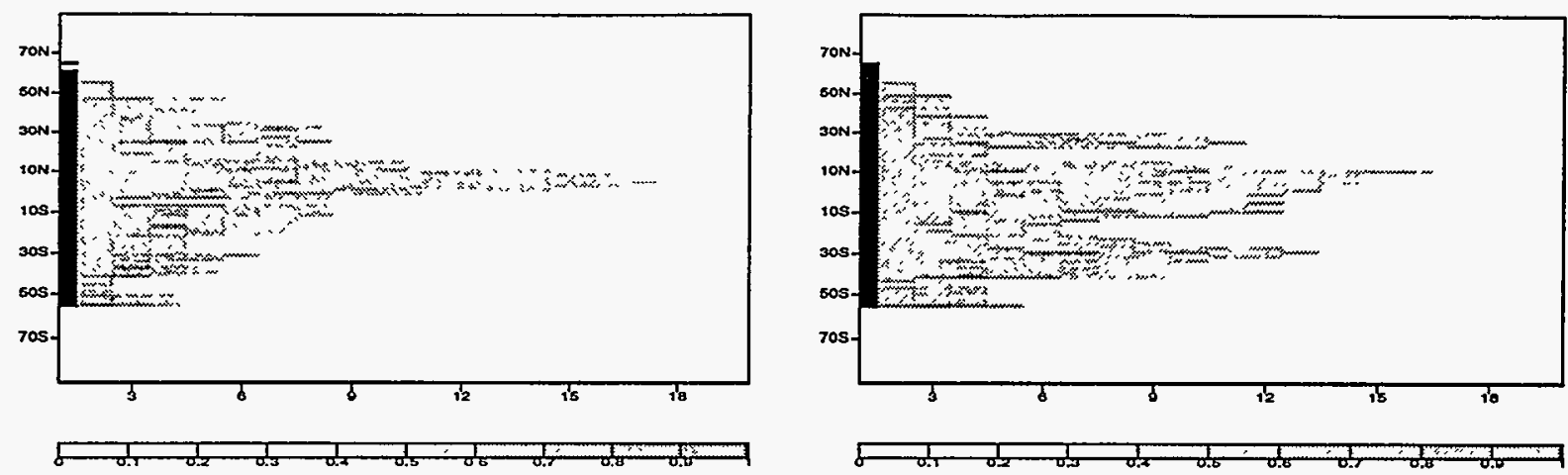

Figure 4: Pacific Ocean lag correlations, as function of latitude, for the departures from the zonal means of: a) cloud cover and b) surface wind speed.

The uncertainties in the zonal average global ocean SW for the four seasons and the annual mean are shown in Fig. 5 in the form of upper and lower error bars. Both random (reduced by the latitude dependent function $g(M))$ and systematic uncertainties are accounted for. Note that even in the tropics the zonal averages systematic uncertainties dominate, which demonstrates the effectiveness of spatial averaging as a means of reducing the magnitude of the random uncertainties. The annual mean zonal average total uncertainties vary from $\pm 10 \mathrm{~W} \mathrm{~m}^{-2}$ in the northern oceans to $\pm 20 \mathrm{~W} \mathrm{~m}^{-2}$ in the tropics.

\subsection{Surface net longwave radiation}

Using an equation similar to Eq. 8, the total uncertainties in the net longwave flux LW have been estimated. In most regions these total LW uncertainties (Fig. 6) are dominated by random uncertainties in $C$; all other random uncertainties are comparatively small. Only in the northern oceans do systematic uncertainties $e, \mathrm{~T}_{\mathrm{a}}, \mathrm{T}_{\mathrm{d}}$ and $\mathrm{T}_{\mathrm{s}}$ compare with the random uncertainty. The zonal annual means of the LW uncertainties are shown in Fig 7. The random uncertainties are principally associated with $C$, and thus they are reduced in a manner analogous to the SW. Note the $L W$ uncertainty estimates are even more subjective than those made for the other heat fluxes. The importance of this deficiency is somewhat diminished by the fact that the magnitude and spatial variation of the LW are much less than those of SW and LH. 

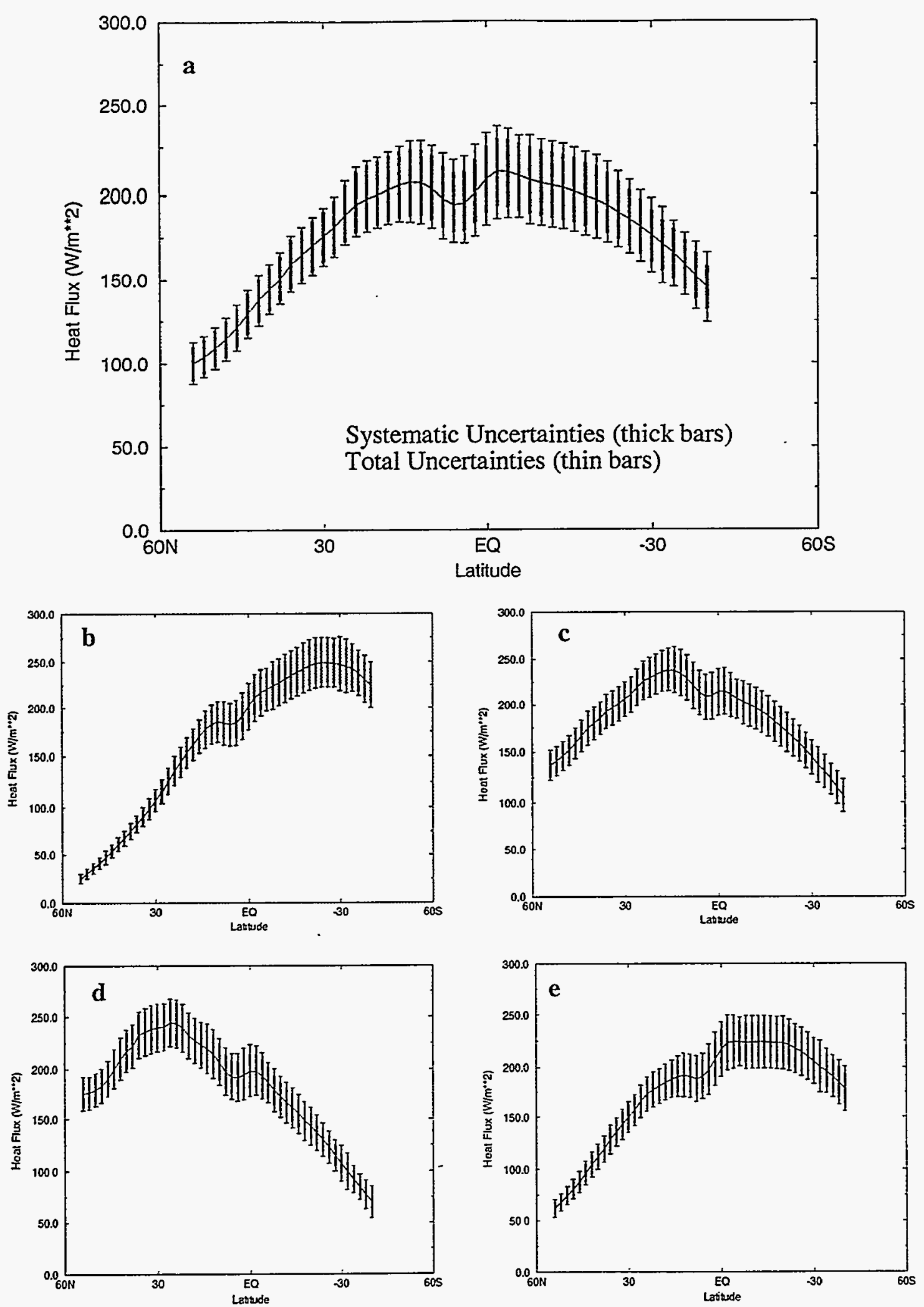

Figure 5: Zonal and climatological annual mean global ocean surface net SW uncertainty bounds for: a) Annual b) DJF c) MAM d) JJA e) SON. 


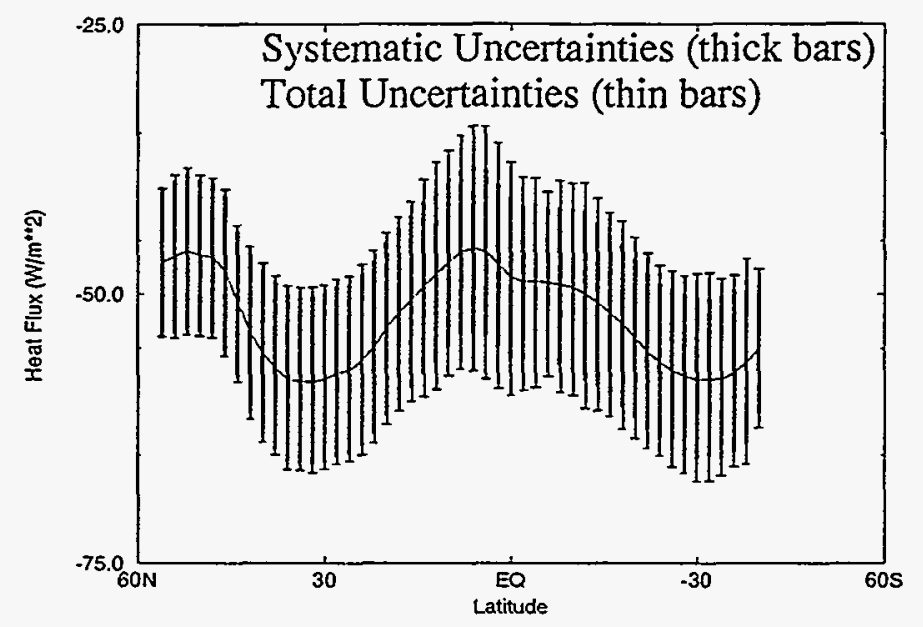

Figure 7: Zonal and climatological annual mean global ocean surface net LW uncertainty bounds.

\subsection{Latent Heat Flux}

Our estimate for the LH uncertainty is based on:

$$
\begin{aligned}
& \sigma_{\mathrm{LH}}=\left[\left(\frac{\partial}{\partial C_{E}} L H \cdot \sigma_{C_{E}, s y s}\right)^{2}+\left(\frac{\partial}{\partial V} L H \cdot \sigma_{s}, s y s\right)^{2}+\left(\frac{\partial}{\partial q_{a}} L H \frac{\partial}{\partial T_{d}} q_{a} \cdot \sigma_{T_{d}}, s y s\right)^{2}\right. \\
& +\left(\frac{\partial}{\partial q_{s}} L H \frac{\partial}{\partial T_{s}} q_{s} \cdot \sigma_{T_{s}, s y s}\right)^{2}+\left(\frac{\partial}{\partial C_{E}} L H \cdot \sigma_{C_{E}, \operatorname{ran}} \cdot f(N)\right)^{2}+\left(\frac{\partial}{\partial V_{s}} L H \cdot \sigma_{V_{s}, \operatorname{ran}} \cdot f(N)\right)^{2} \\
& +\left(\frac{\partial}{\partial q_{a}} L H \frac{\partial}{\partial T_{d}} q_{a} \cdot \sigma_{T_{d}, r a n} \cdot f(N)\right)^{2}+\left(\frac{\partial}{\partial q_{s}} L H \frac{\partial}{\partial T_{s}} q_{s} \cdot \sigma_{T_{s}, \text { ran }} \cdot f(N)\right)^{2} \\
& \left.+2\left(\rho_{V_{s}, q_{a}-q_{s}} \frac{\partial}{\partial V_{s}} L H \cdot \frac{\partial}{\partial\left(q_{a}-q_{s}\right.}\right)^{L H \sigma_{V}} \cdot \sigma_{q_{a}}-q_{s, s y s}\right)^{2} \\
& \left.+2\left(\rho_{V_{s}, q_{a}-q_{s}} \frac{\partial}{\partial V_{s}} L H \cdot \frac{\partial}{\partial\left(q_{a}-q_{s}\right)} L H \sigma_{V_{s}} \cdot \sigma_{q_{a}-q_{s, \text { ran }}} f(N)\right)^{2}\right]^{1 / 2}
\end{aligned}
$$

The three largest uncertainties related to the LH flux, all of which are systematic, are shown in Fig. 8. In contrast to our findings for the radiative fluxes, the LH random uncertainties (not shown) in all regions are small in comparison to the systematic uncertainties. Figure $8 \mathrm{a}$ shows the annual mean systematic uncertainty due to the exchange coefficient, $\mathrm{C}_{\mathrm{E}}$. In the northern oceans they are less than $10 \mathrm{~W} \mathrm{~m}^{-2}$ in many areas, but in the tropics and midlatitudes the uncertainties are in excess of $15 \mathrm{~W} \mathrm{~m} \mathrm{~m}^{-2}$. Over the western boundary currents they are greater than $20 \mathrm{~W} \mathrm{~m}^{-2}$. The systematic uncertainty in the LH flux due the surface wind speed, which is shown in Fig. 8b, is 
evidently the most serious source of systematic errors. In many regions these uncertainties are greater than those due to the exchange coefficient, exceeding $20 \mathrm{~W} \mathrm{~m}^{-2}$ in much of the tropics. In the eastern portion of the mid-latitude oceans the uncertainties are smaller than in the west because the uncertainties are a function of the flux itself and LH is generally higher in the west owing to the relatively dry air flowing eastwards off the continents over the western boundary currents. Systematic uncertainties due to $\left(T_{d}-T_{s}\right)$ and from the correlation between surface $V_{s}$ and $\left(T_{d}-T_{s}\right)$ are combined and shown in Fig $8 \mathrm{c}$. The correlation is calculated using the 30 monthly means for each calendar month (monthly values of $\overline{V_{s} \cdot\left(T_{d}-T_{s}\right)}$ are available), and is small in most areas except over the western boundary currents. The resulting uncertainties are much smaller than those in Figs. $8 \mathrm{a}$ and $8 \mathrm{~b}$. Correlation uncertainties between $\mathrm{C}_{\mathrm{E}}$ and $\mathrm{V}_{\mathrm{s}}$ or $\left(\mathrm{T}_{\mathrm{d}}-\mathrm{T}_{\mathrm{s}}\right)$ are similar to those between $V_{s}$ and $\left(T_{d}-T_{s}\right)$. The total LH uncertainties are shown in Fig. 8d. Nowhere are they less than $10 \mathrm{~W} \mathrm{~m}^{-2}$, and in western tropical oceans they exceed $30 \mathrm{~W} \mathrm{~m}^{-2}$. Along the western boundary currents the total LH flux uncertainty is nearly $50 \mathrm{~W} \mathrm{~m}^{-2}$. These results do not suggest that more of the same types of observations would substantially reduce LH uncertainties, but rather that methods to correct for existing errors are necessary. $V_{s}$ estimates may improve (e.g., Isemer and Hasse, 1991), but prospects for reducing exchange coefficient uncertainties are less encouraging. Finally, it is important to note that the exchange coefficient uncertainties are dependent on the uncertainties in $\mathrm{V}_{\mathrm{s}}$ and thus the relative importance of these two terms (Figs. 8a and 8b) must be considered carefully. Further tests are necessary.

The zonal mean LH flux uncertainties for the annual and seasonal means are shown in Fig. 9. We we have reduced the zonal average uncertainties associated with $V_{s}$ in the same manner as we did with $C$ in the $S W$ and $L W$ because it is possible that the random uncertainty associated with a visual $\mathrm{V}_{\mathrm{s}}$ estimate is a function of $\mathrm{V}_{\mathrm{s}}$ itself. The corresponding (see section 4.1) $\mathrm{V}_{\mathrm{s}}$ lag correlations are shown in Figure $4 \mathrm{~b}$. At $30^{\circ} \mathrm{N}$ the estimated number of degrees of freedom is $\mathrm{M} / 10$, based on the same criteria $\left(\mathrm{L}_{\text {cuttoff }}=0.4\right)$ used for the lag correlations of $C$. 

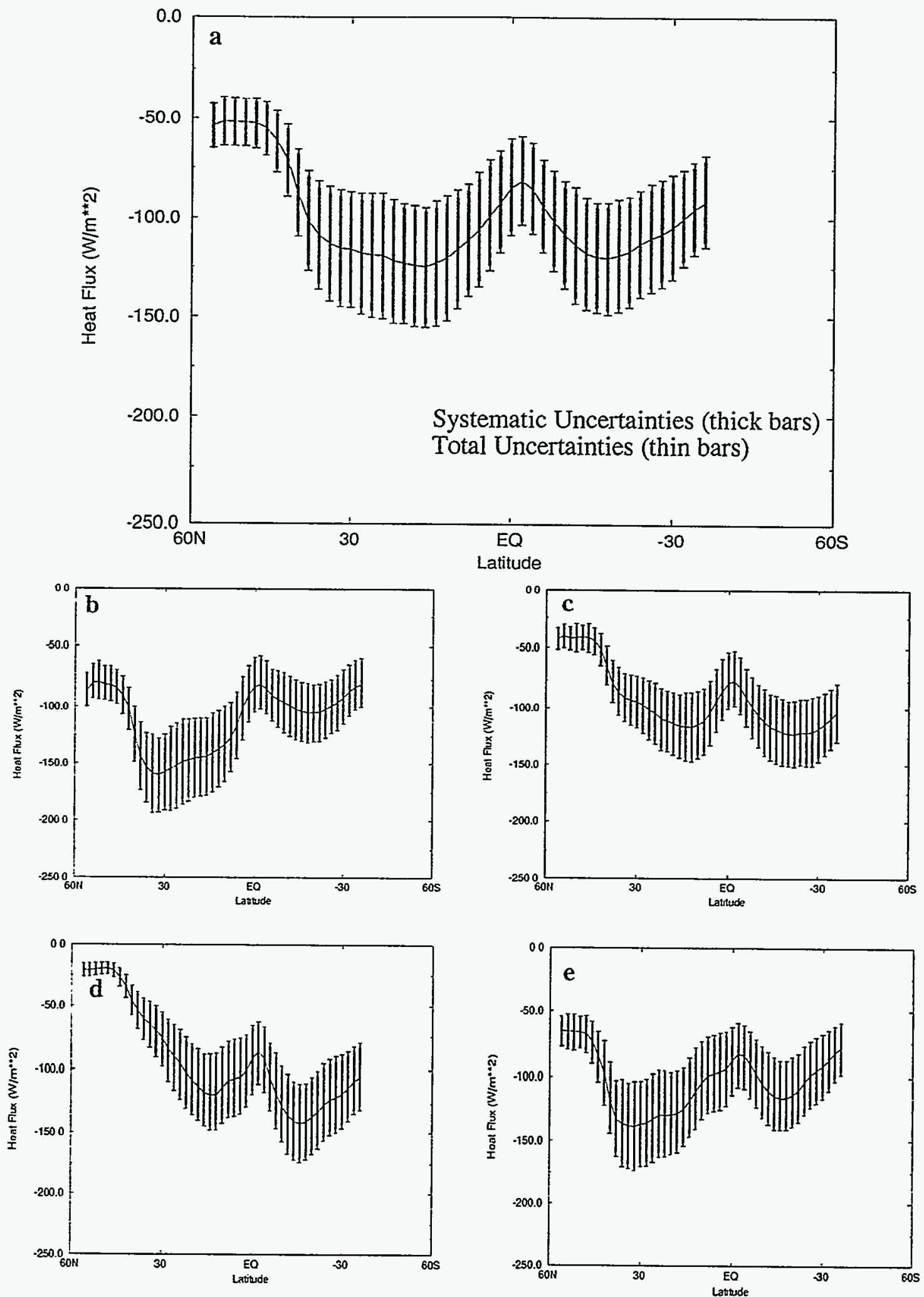

Figure 9: Zonal and climatological global ocean surface LH uncertainty bounds for: a) Annual b) DJF c) MAM d) JJA e) SON. 
The random uncertainties resulting from all temperature measurements are presumed to have little spatial dependence, as they were recorded under many different circumstances (observers, instruments and times). They were consequently reduced as $\mathrm{M}^{-1 / 2}$ and are barely discernible in the zonal mean figures. Unfortunately, even though we can justify reducing the random uncertainties substantially, the zonal means of the total LH uncertainties are at least $\pm 25 \mathrm{~W} \mathrm{~m}^{-2}$ at most latitudes.

\subsection{Sensible Heat Flux}

The SH systematic uncertainties due to the exchange coefficient are shown in Fig. 10a, and in Fig. $10 \mathrm{~b}$ both the $\left(\mathrm{T}_{\mathrm{a}}-\mathrm{T}_{\mathrm{s}}\right)$ and $\mathrm{V}_{\mathrm{s}}$ systematic uncertainties are shown. The absolute uncertainties in both figures are small, but the relative uncertainties are at least as large as those of the LH flux. All random uncertainties and the correlated uncertainties between $V_{s}$ and $\left(T_{a}-T_{s}\right)$ are included in the total SH uncertainties in Fig. 10c. Over the western boundary currents the total uncertainties are in excess of $15 \mathrm{~W} \mathrm{~m}^{-2}$, but elsewhere they range between 5 and $10 \mathrm{~W} \mathrm{~m}^{-2}$. The relative importance of the random and systematic uncertainties is analogous to that of the LH. The annual mean zonal averages of the SH flux uncertainties are shown in Fig. 11.

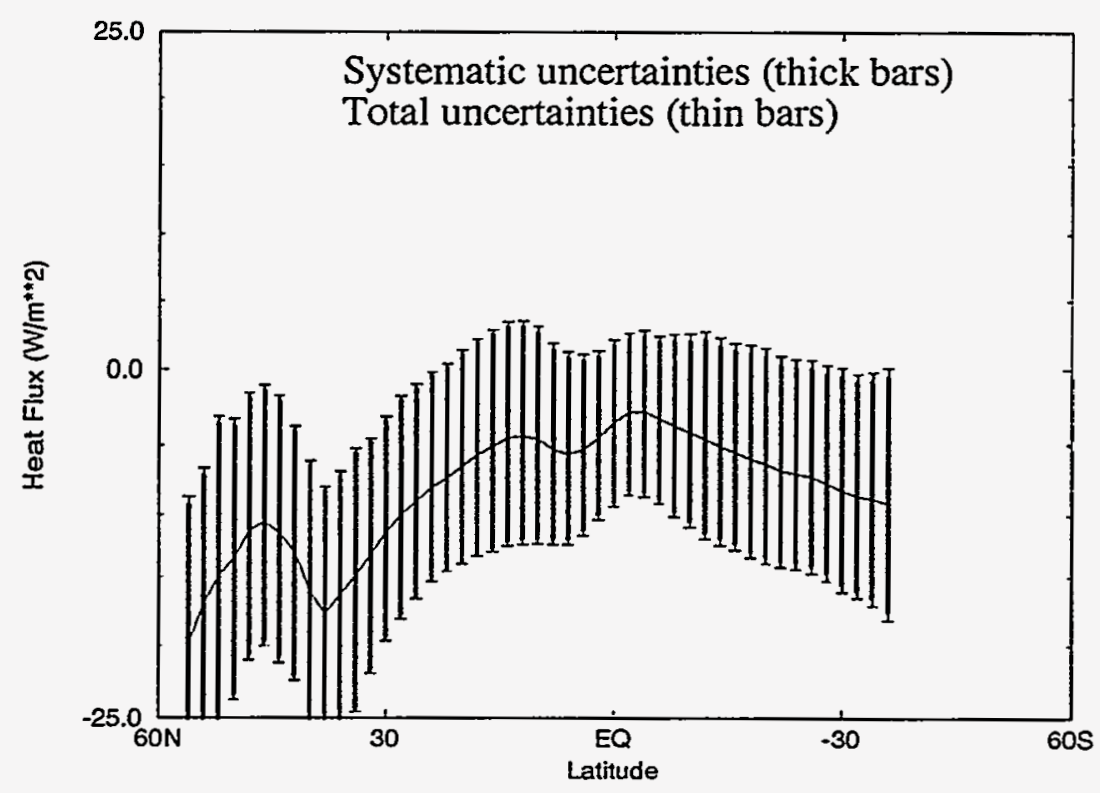

Figure 11: Zonal and climatological annual mean global ocean surface SH uncertainty bounds. 


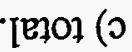

ọ̣euəłs

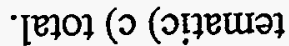

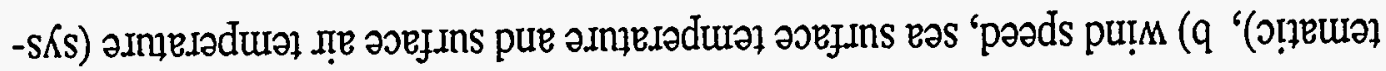

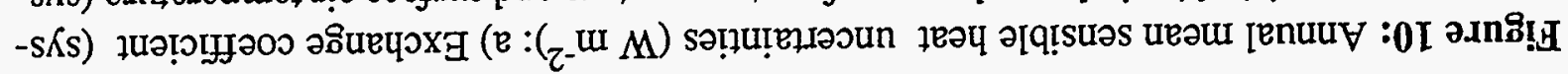
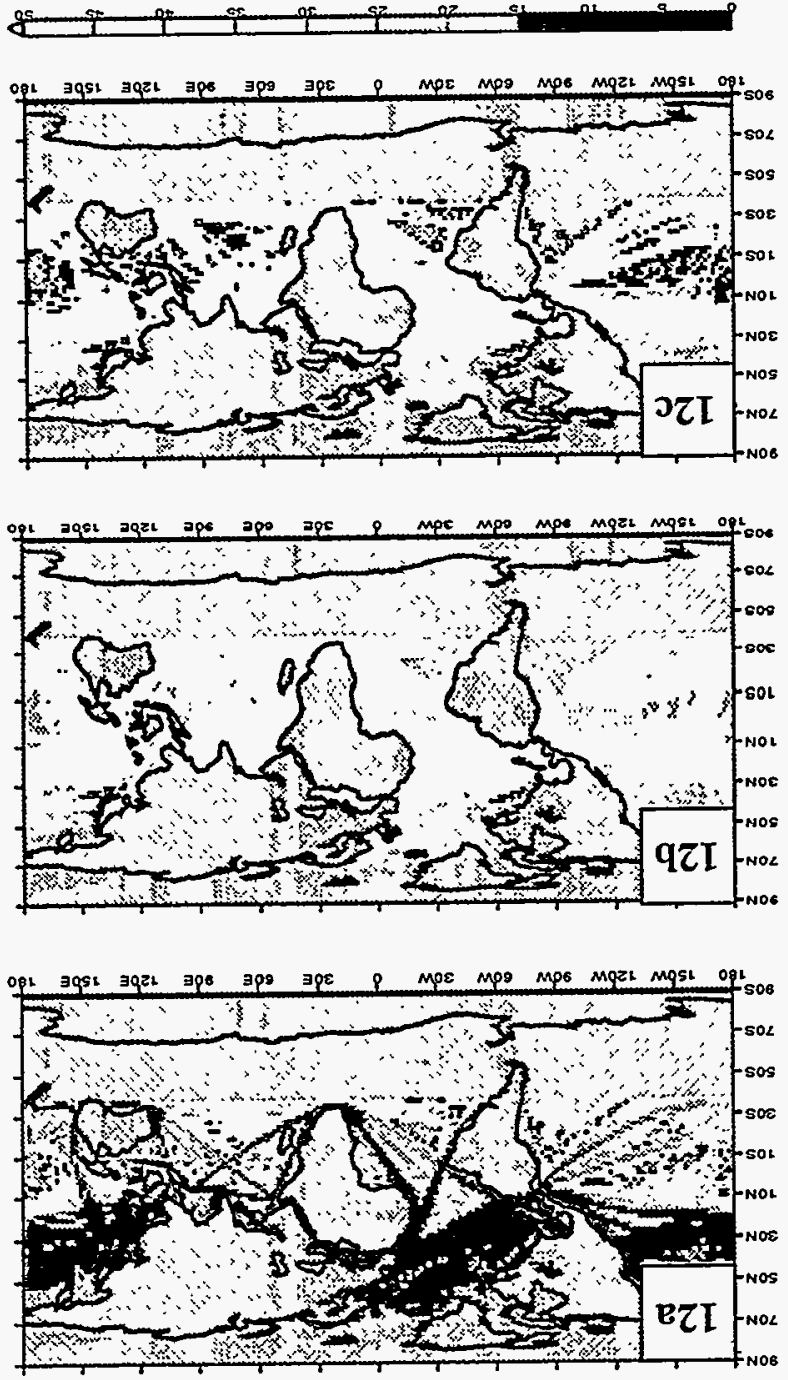
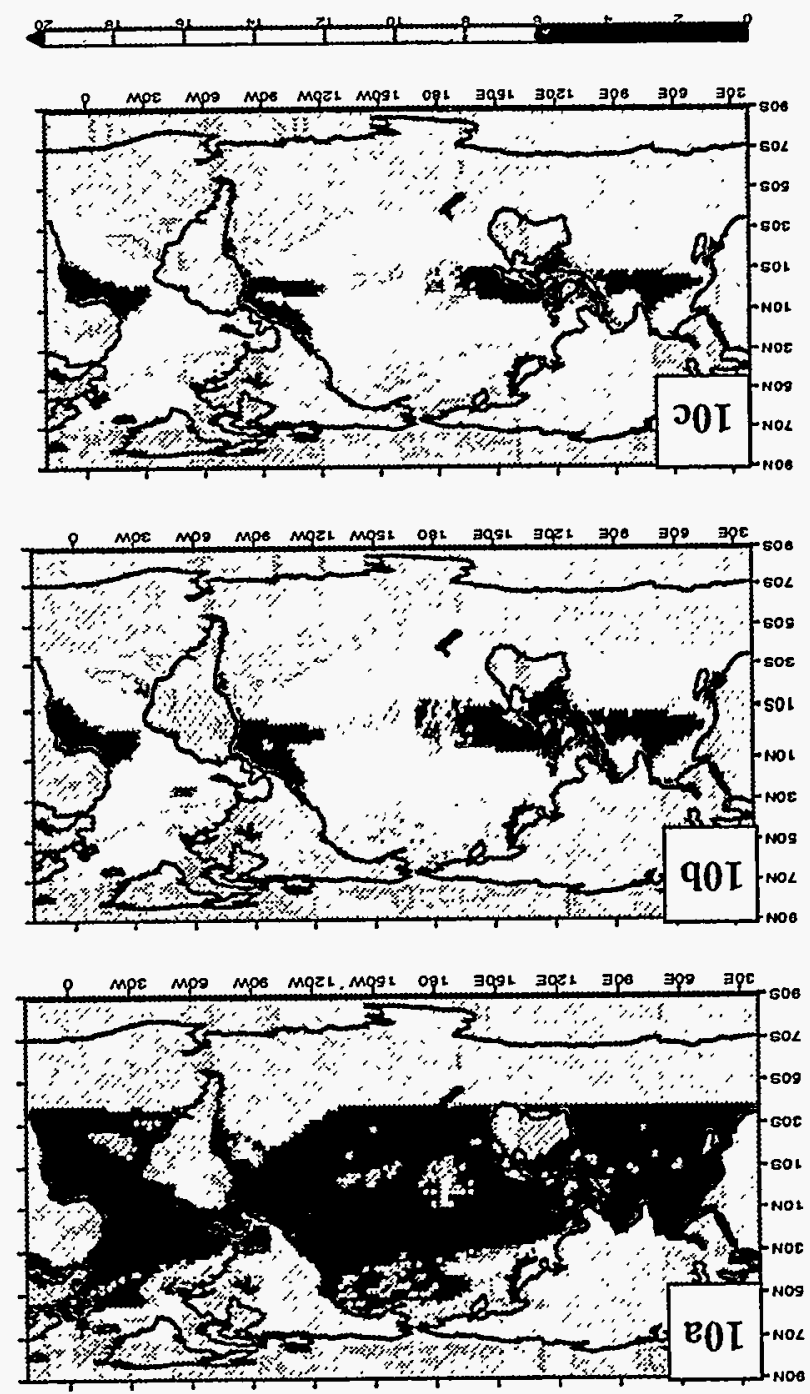


\subsection{Net Surface Heat Flux}

To estimate the propagation of uncertainties into the net surface heat flux, we must account for possible correlations between each component of the surface energy balance:

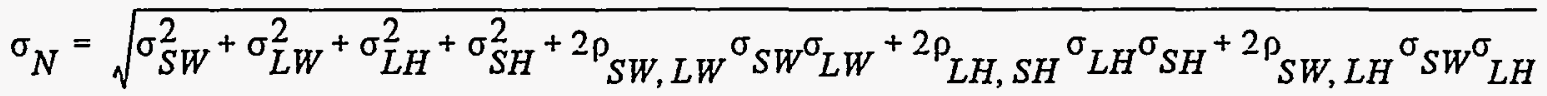

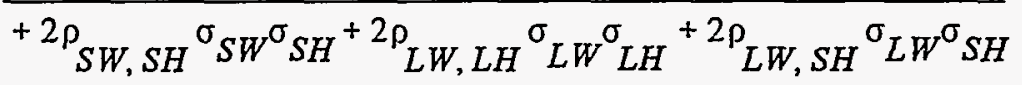

The partial derivatives in the correlation terms (compare with Eq. 6) are not included in Eq.

11 because they are all unity (e.g., $\frac{\partial}{\partial N} S W \cdot \frac{\partial}{\partial N} L W=1 \cdot 1$ ). Tests suggest that only the first two correlation terms $\left(\rho_{\mathrm{SW}, \mathrm{LW}}\right.$ and $\left.\rho_{\mathrm{LH}, \mathrm{SH}}\right)$ have an effect on our estimate of $\sigma_{\mathrm{N}}$ which is not negligible. The LH and SH uncertainties are clearly correlated to some degree since they both result from uncertainties in surface wind speed measurements and both exchange coefficients are dependent on estimates of atmospheric stability in the boundary layer. For each calendar month we calculated the correlation for the 30 years of data between $V_{s}\left(q_{a}-q_{s}\right)$ and $V_{s}\left(T_{a}-T_{s}\right)$ and have used this as a measure for $\rho_{\mathrm{LH}, \mathrm{SH}}$. In most regions $\rho_{\mathrm{LH}, \mathrm{SH}}$ was less than 0.25 , but a notable exception was a rather high correlation (0.6-0.7) over the western boundary currents in the winter months.

Another potentially important correlation exists between the SW and LW estimates because both parameterizations are strong functions of $C$. Ideally we would estimate $\rho_{S W, L W}$ as we did $\rho_{\mathrm{LH}, \mathrm{SH}}$ because it gives us a measure of the correlation at each grid point. Instead, we have estimated $\rho_{S W, L W}$ for each month based on the spatial correlation between SW and LW along each line of latitude because not all the time averaged quantities needed (e.g., $\overline{T_{s}^{4} e_{s} c^{2}}$ ) to make the gridpoint calculation are available via the COADS summary. There is a rather strong anti-correlation at most latitudes $(-0.5$ to -0.95$)$ because the downward (and consequently the net) LW increases with $C$ as SW decreases. The negative correlation leads to a minor reduction in the estimate of $\sigma_{\mathrm{N}}$.

Figures $12 \mathrm{a}-12 \mathrm{c}$ show the random uncertainties, the systematic uncertainties, and the total uncertainties in the net surface heat flux. The random uncertainties range from $5-15 \mathrm{~W} \mathrm{~m}^{-2}$ in the 

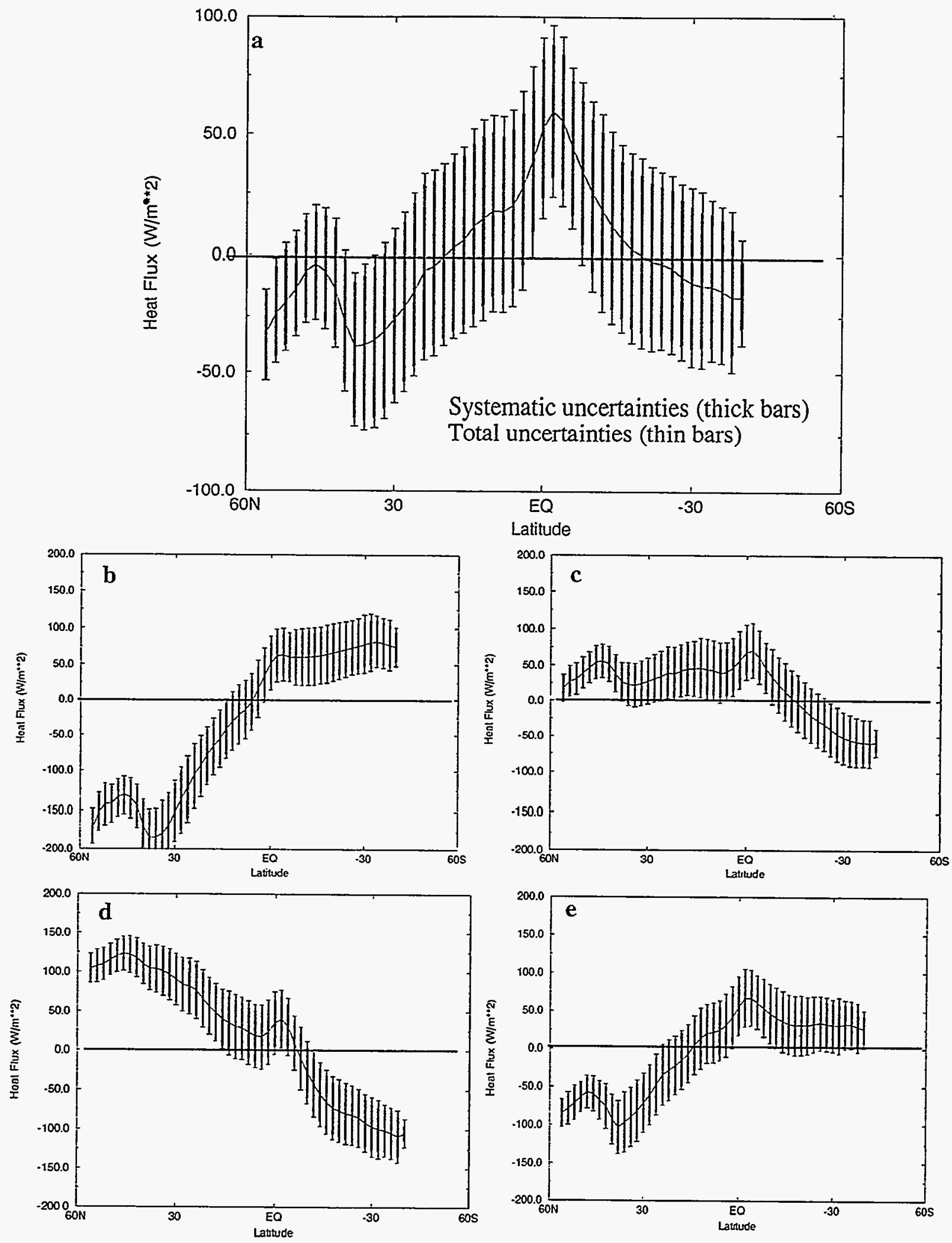

Figure 13: Zonal and climatological mean global ocean surface net heat flux uncertainty bounds for: a) Annual b) DJF c) MAM d) JJA e) SON. 
northern oceans to $25-50 \mathrm{~W} \mathrm{~m}^{-2}$ in the tropics and subtropics. The systematic uncertainties are between 15 and $30 \mathrm{~W} \mathrm{~m}^{-2}$ in the northern oceans and between 30 and $45 \mathrm{~W} \mathrm{~m}^{-2}$ elsewhere, except the western boundary currents where they are in excess of $50 \mathrm{~W} \mathrm{~m}^{-2}$. Thus both random and systematic uncertainties are important in the net heat flux, although the systematic uncertainties are larger in most regions. Zonal mean uncertainties for the net surface heat flux are shown in Figs. 13a-e. Note that at most latitudes the uncertainties suggest than not even the sign of the annual mean net surface heat flux is known.

\section{Discussion}

A methodology to define uncertainties associated with ocean surface heat flux calculations has been developed and applied to a revised version of the Oberhuber(1988) global climatology, which utilizes a summary of the COADS surface observations. Systematic and random uncertainties in the net oceanic heat flux and each of its four components at individual grid points and for zonal averages have been estimated for each calendar month and the annual mean.

The most important uncertainties of the $2^{\circ} \times 2^{\circ}$ grid cell values of each of the heat fluxes are described. Random uncertainties in the annual mean net shortwave flux associated with errors in estimating cloudiness in the tropics yield total uncertainties which are greater than $25 \mathrm{Wm}^{-2}$. In the northern latitudes where the large number of observations substantially reduce the influence of these random errors, the systematic uncertainties associated with the utilized parameterization are largely responsible for total uncertainties in the shortwave fluxes which usually remain greater than $15 \mathrm{Wm}^{-2}$. In the zonal means the systematic uncertainties are the most important at all latitudes, because the spatial averaging has led to a further reduction of the random errors. The situation for the annual mean latent heat flux is somewhat different in that even for grid point values the contributions of the systematic uncertainties tend to be larger than those of the random uncertainties at all but the highest northern latitude locations. Uncertainties in latent heat flux are greater than about $20 \mathrm{Wm}^{-2}$ for nearly all locations south of $40^{\circ} \mathrm{N}$ and in excess of $30 \mathrm{Wm}^{-2}$ over broad areas 
of the subtropics, even those with large numbers of observations. The resulting zonal mean uncertainties of latent heat flux are largest $\left(\sim 30 \mathrm{Wm}^{-2}\right)$ in the middle latitudes and subtropics and smallest $\left(\sim 15-25 \mathrm{Wm}^{-2}\right)$ near the equator and over the northernmost regions.

One of the primary goals of this research has been to introduce a methodology which provides an improved means of evaluating the agreement between observations of surface heat fluxes and those simulated by atmospheric and oceanic general circulation models (GCMs). Simulated surface energy fluxes have been found to vary tremendously (cf. Lambert and Boer, 1989; Gleckler, 1995). Preliminary results in the validation of surface heat fluxes as simulated by 30 atmospheric GCMs in the Atmospheric Model Intercomparison Project (AMIP; Gates, 1992, Randall and Gleckler, 1995) suggest that our calculated uncertainties will prove to be useful in the evaluation of model simulations. Two examples are illustrated in Fig. 14 showing the total uncertainties based on the modified Oberhuber atlas and the 30 AMIP-model means with the one standard deviation ranges of the individual model results about those means. For the annual mean net surface shortwave flux, Fig. 14a shows that the mean model values are greater than the adjusted Oberhuber estimates plus our calculated uncertainties $\left(\mathrm{SW}+\sigma_{\mathrm{SW}}\right)$ at all extratropical latitudes. Furthermore, in the mid latitudes very few models have surface shortwave fluxes in the range of the observations. Fig. $14 \mathrm{~b}$ shows a similar comparison for the simulated and estimated DJF latent heat fluxes. Despite the fact that our uncertainty estimates for the LH are very large, they suggest that south of about $20^{\circ} \mathrm{N}$, the mean of the models yields a rate of evaporation which is greater than our uncertainty bounds. In the low latitudes, the evaporation in virtually all models exceeds our range of uncertainties. It is interesting to note that the apparent biases in the surface shortwave and latent heat seem compensatory. This is however likely to be coincidence, because the latent heat flux is largely constrained by the SSTs, which are prescribed and therefore independant of the simulated surface radiative fluxes.

The confidence that can be placed in a comparison such as shown in Fig. 14 depends upon the calculated uncertainties and the mean values of the chosen climatology. The uncertainties are based upon: 1) estimates available from the published literature of the fundamental uncertainties 

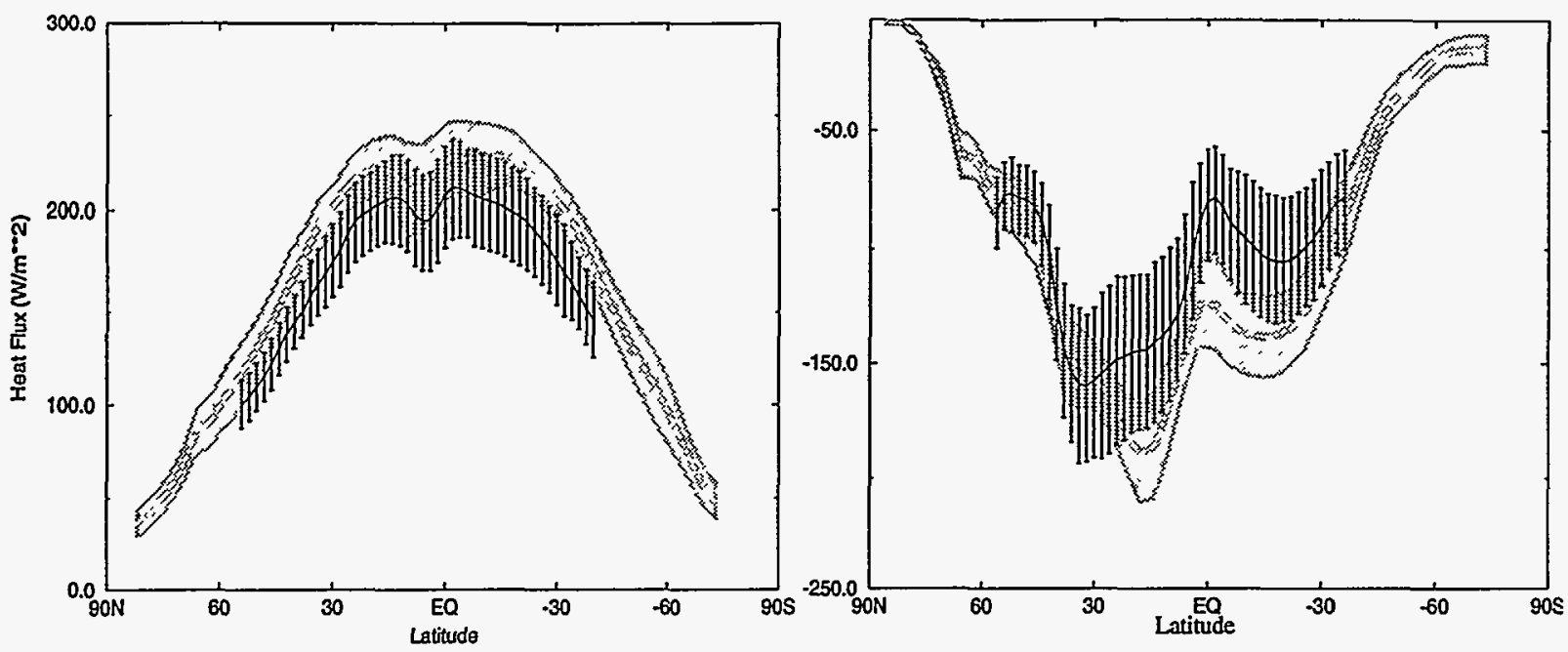

Figure 14: Zonal and climatological mean global ocean surface flux (white line is the adjusted Oberhuber) uncertainties (error bars) and the average (black line) \pm one standard deviation (shading) of the AMIP simulations for a) annual mean net shortwave and b) DJF latent heat.

in the basic observations and parameterizations used in the heat flux calculations, and 2) statistical analyses of the COADS summary to reduce random uncertainties in space and time. Actual uncertainties likely differ from one atlas to another depending on the choice of parameterizations, bias corrections in the observations, methodology ("classical" versus "sampling"), etc. However, it is our belief that this analysis illuminates the relative importance of fundamental uncertainties and how they vary in both space and time. We expect that repeating this anaylsis with other atlases would yield similar results. The mean flux estimates of the different atlases could yield "DC shifts" in our uncertainty estimates, and this relates back to the confidence one can place on a comparison of our uncertainties with models such as in Fig 14. Clearly, further tests are necessary, but the methodology outlined here provides a quantatative approach to evaluate the reliability of flux estimates, and could be refined and applied to future flux climatologies.

The largest influences in the magnitudes of all of the illustrated uncertainty estimates are our choices of the fundamental uncertainties listed in Tables 1 and 2. The estimates of the systematic uncertainties in the basic observations and the parameterizations are not only difficult to establish, but are strongly influenced by attempts to correct for one or more of recognized systematic errors. One of the best researched systematic errors is that associated with the conversions of Beaufort estimates of sea state to wind speeds. This has been the subject of a recent international work- 


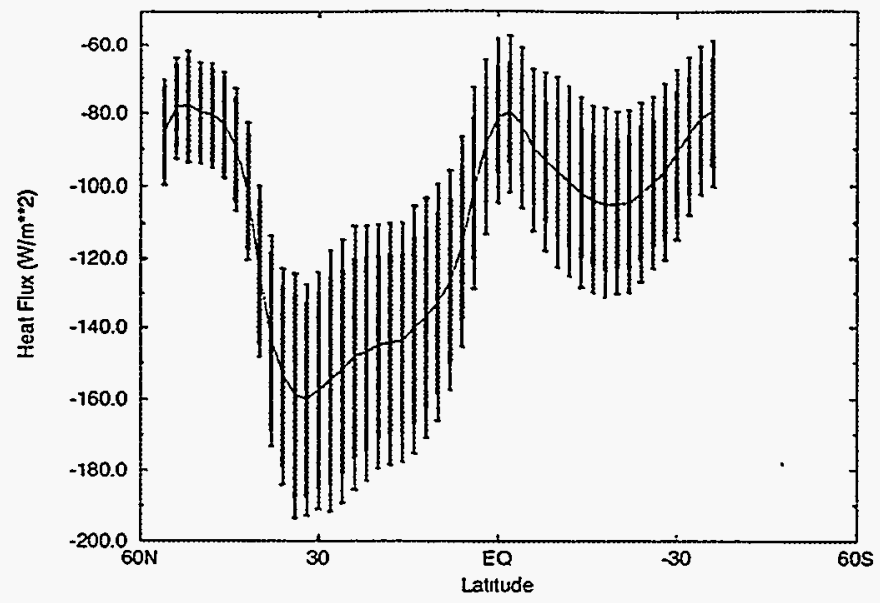

Figure 15: Zonal and annual mean global ocean total LH flux uncertainty (thin bars) and that due to all terms except the systematic surface wind speed uncertainty (thick bars).

shop (Diaz and Isemer, 1995). As a consequence of this and related work da Silva(1994) in his recent climatology chose to remove as much as possible this bias by an adjustment to the reported wind speeds. The maximum affect on our estimated uncertainties of this adjustment has been estimated by repeating our analysis of the total uncertainties in the latent heat flux with the systematic uncertainty of wind speed in Table 1 set to zero. Fig. 15 illustrates the zonally averaged uncertainties about the Oberhuber mean DJF latent heat fluxes based on calculations with and without an assumed systematic uncertainty in wind speed. This figure suggests that reducing the biases associated with wind speed estimates is helpful, but the uncertainties in the LH remain large due to the uncertaitnies in the exchange coefficient and the air-sea moisture gradient.

In our analysis the Wright COADS summary was used to calculate the correlations utilized in equations such as (11) and (12) and the $g(M)$ factor in (10). Results using another climatology are likely to be very similar since there is no reason to believe that these correlations are sensitive to the time period or total number of the observations. Our zonal average results may be influenced by our rather arbitrary choice of a cutoff of correlation of 0.4 to estimate the number of degrees of freedom associated with the reduction in the influence of the random uncertainties, but tests have suggested that the uncertainty estimates are not highly sensitive to this critereon.

The mean values of the Oberhuber analysis also depended upon a prior assessment of the possible systematic biases in the observations and parameterizations and attempts to adjust for 
them. For example, the turbulent exchange coefficients for $\mathrm{LH}$ and $\mathrm{SH}$ in the atlases of Oberhuber and others are believed by many to be too high (Isemer et al., 1989). High values of $\mathrm{C}_{\mathrm{E}}$ and $\mathrm{C}_{\mathrm{H}}$ were apparently needed to compensate for the wind speed estimates being systematically too low (Isemer and Hasse, 1991). These two biases tend to compensate for each other in the calculation of the mean. Given the remaining controversies, we have retained both of these biases in our analysis. A future application of this analysis may yield a different perspecitve of the relative importance of these uncertainties.

Some authors (Darnel et al., 1992) have argued that the greatest potential for improvements in global long term mean estimates of surface heat fluxes are through the use of satellite observations. Our results tend to confirm this assertion with respect to the radiative fluxes. Fig. 3 illustrates that at individual grid points the uncertainties in the shortwave flux is dominated by the random uncertainties associated with estimates of cloud fraction. A number of authors (e.g. Li, 1993 and Chartock, 1992) have pointed out that these can be reduced considerably by the use of high resolution, frequent satellite observations of reflected solar radiation. Satellite observations are less useful in estimating surface longwave radiation (Darnel et al. 1992), but they too may produce estimates with smaller random errors. For the moment it is not clear if satellite estimates of surface radiative fluxes have smaller systematic biases than those associated with the parameterizations utilized herein. On the other hand, the modeled cloudy-sky SW absoprtion utilized in all satellite-derived estimates of surface shortwave radiation has recently been questioned (Cess et al., 1995), and thus at present surface based estimates may be more reliable.

Our results are less encouraging concerning the possiblity of satellite measurements helping to reduce the uncertainties in the latent heat flux. As is illustrated in Figs. 8 and 9 the largest contributions to the LH uncertainties are the systematic uncertainties associated with the basic observations and the parameterizations. Satellite-based methodologies for estimating the fluxes (Liu, 1988) rely upon the same bulk parameterizations used with surface observations together with satellite estimates of the fundamental variables of wind speed, temperatures and humidities. Since the systematic uncertainties in the parameterizations remain the same as those discussed here and 
the systematic uncertainties of satellite estimates of wind speeds and humidities are not insignificant, these satellite estimates are unlikely smaller uncertainties than the surface based estimates. They are however proving to be useful for studies of variability (e.g., Liu et al., 1992).

In addition to helping in the evaluation of surface heat fluxes simulated by general circulation models, the methodology outlined here allows one to interpret the relative importance of the various errors accumulated in large scale surface heat flux estimates and how they vary in space and in time. It may therefore be helpful in the development of a strategy for practical future observational programs. At this point the uncertainty estimates resulting from the application of the method are only meant to provide rough guidelines of the reliability of our surface based observational estimates of ocean surface heat fluxes. It is expected that they will be fine-tuned and hopefully reduced in the years to come. Some possible biases have not been quantified here (such as use of the 'classical method'), and will need to be evaluated in future applications of this method.

Observational programs such as the Tropical Ocean Global Atmosphere (TOGA), the World Ocean Circulation Experiment (WOCE) and the Global Energy and Water Experiment (GEWEX) are expected to yield a wealth of information for the analysis surface heat fluxes. However, for the moment there appears little hope that the deficiencies in our ability to measure surface heat fluxes on a global scale will improve by as much as $50 \%$. Despite this rather discouraging scenario, development of new products using improved parameterizations and corrections for biases in available data is important. They are in fact necessary steps towards improving our understanding. Moreover, improved observational products may also be attainable even with existing resources. Taylor et el. (WCRP-23, 1989) have outlined strategies for standardizing procedures of VOF measurements, and have suggested that it may be possible to optimize the utility of the global scale network of VOF data simply by further improving procedural and instrumentation standards. For this reason, the Intergovernmental Oceanographic Commision and the World Meteorological Organization have jointly established the Ocean Observing Development Panel.

Uncertainty estimates for zonal average surface energy fluxes can be obtained from the corresponding author as monthly, seasonal or annual means for each ocean basin. 
Acknowledgments: This work was performed under the auspices of the Department of Energy Environmental Sciences Division by the Lawrence Livermore National Laboratory under contract W7405-ENG-48. We are grateful to the many who have enabled us to make use of their data. 


\section{REFERENCES}

Anderson R.J. and S.D. Smith, 1981: Evaporation coefficient for the sea surface from eddy flux measurements. J. Geophys.Res., 86, 449-456.

Atwater, M.A. and Ball, J.T., 1981: Sensitivity of computed incoming solar radiation at the surface to cloud analyses. Mon.Wea.Rev., 109, 889-894.

Blanc, T.V., 1987: Accuracy of Bulk-Method-Determined Flux, Stability and Roughness. J. Geophys. Res., 92, 3867-3876.

Berliand, T. C., 1960: Method of climatolgical estimation of global radiation. Meteor. Gidrol., 6, 9-12.

Cayan, D.R., 1992a: Latent and sensible heat flux anomalies over the northern oceans: the connection to the monthly atmospheric circulation. J. Climate, 5, 354-369.

Cayan, D.R., 1992b: Variability of latent and sensible heat fluxes estimated using bulk formulae. Atmos.-Ocean, 30, 1-42.

Cess, R.D., M.H. Zhang, P. Minnis, L. Corsetti, E.G. Dutton, B.W. Forgan, D.P. Garber, W.L. Gates, J.J. Hack, E.F. Harrison, X. Jing, J.T. Kiehl, C.N. Long, J.-J.Morcrette, G.L. Potter, V. Ramanathan, B. Subasilar, C.H. Whitlock, D.F. Young, Y.Zhou, 1995: Absorption of solar radiation by clouds: observations versus models. Science, 267, 496-498.

Chertock, B., R. Frouin, and C. Gautier, 1992: A technique for global monitoring of net solar irradiance at the ocean surface. Part II: Validation. J.Appl. Meteor., 31, 1067-1083.

Darnel, W.L., W. Staylor, N. Retchey, A. Wibler, 1992: Seasonal variation of surface radiation budget derived from the International Satellite Cloud Climatology Project $\mathrm{C} 1$ data. J. Geophys. Res., 97, 15,741-15,600.

da Silva, A.M., C.C. Young and S. Levitus, 1995: Atlas of Marine Surface Data, Vol. 2. U.S. Government Printing Office, Wash. DC (in press).

Davies, J. A., Abdel-Wahab, M., and McKay, and Howard, J.E., 1985: Cloud transmissivities for Canada. Mon.Wea.Rev., 113, 338-348.

Diaz H.F. and H.-J. Isemer, (Eds.) Proceedings of the international COADS winds workshop, Kiel, Germany, 31 May - 2 June 1994.

Dobson, F.W. and S.D. Smith, 1988: Bulk models of solar radiation at sea. Q.J.R. Meteorol.Soc., 114, 165-182. 
Dobson, F.W., F.P. Bretherton, D.M. Burridge, J. Crease, E.B. Kraus and T.H. Vonder Haar, 1982: The 'CAGE' experiment: a feasibility study. World Meteorolgovical Organisation, Geneva. WCP-22.

Esbensen S.K. and Y. Kushnir, 1981: The heat budget of the global ocean: An atlas based on estimates from surface marine observations. Oregon State University, Climate Research Institute, Report No. 29

Esbensen S.K. and R.W. Reynolds, 1981: Estimating monthly averaged air-sea transfers of heat an momentum using the bulk aerodynamic method. J. Phys. Oceanogr., 11, 457-465.

Fissel, D. B., S. Pond, and M. Miyake, 1977: Computation of surface fluxes from climatological and synoptic data. Mon.Wea.Rev, 105,26-36.

Frohlich, C. and J. London, 1986: Revised intsruction manual on radiation instruments and measurments. World Meteorological Organisation, Geneva. WCRP Pub. Ser. 7.

Fung, I., D.E. Harrison, and A. A. Lacis, 1984: On the variability of net longwave radiation at the sea surface. Revs.Geophys.Space.Phys., 22, 177-193

Gates, W.L, 1992: AMIP: The Atmospheric Model Intercomparison Project. Bull. Amer. Meteor.Soc., 73, 1962-1970.

Gleckler, P.J., D.A. Randall, G. Boer, R. Colman, M.Dix, V. Galin, M. Helfand, J. Kiehl, A. Kitoh, W. Lau, X.-Z. Liang, V. Lykossov, B. McAvaney, K. Miyakoda, S. Planton and W. Stern, 1995: Cloud-Radiative Effects on implied oceanic energy transports as simulated by atmospheric general circulation models. Geo.Res.Lets. 22, 791-794.

Gulev, S.R., 1994: Influence of space-time averaging on the ocean-atmosphere exchange estimates in the North Atlantic midlatitudes. J. Phys. Oceanogr., 24, 1236-1255.

Hahn, C.J., S.G. Warren and J. London, 1995: The effect of moonlight on observation of cloud cover at night, and application to cloud climatology. J. Clim., 8, 1429-1446.

Hanwana, K., 1987: Critical examination of estimation methods of long-term mean air-sea heat and momentum in the sea south of Japan. J. Meteorol. Soc. Japan., 65, 767-775.

Hsiung, J., 1986: Mean surface energy fluxes over the global ocean. J. Geophys. Res., 91, 10,585$10,606$.

Isemer, H.J and L. Hasse, 1991: The scientific Beaufort equivalent scale: Effects on wind statistics and climatological air-sea flux estimates in the North Atlantic Ocean. J.Clim., 4, 819-836. 
Isemer, H.J., J. Willebrand and L. Hasse, 1989: Fine adjustment of large scale air-sea energy flux parameterizations by direct estimates of ocean heat transport. J: Clim., 2, 1173-1184.

Jones, P.D., T.M.L. Wigley, G Farmer, 1991: Marine and land temperature data sets" A comprehensive look at recent trends. Greenhouse-Gas-Induced Climatic Change: A critical appraisal of simulations and observations. (Ed. M.E. Schlesinger). Amsterdam, Holland: Elsevier

Josey, S.A., E.C. Kent, and P.K. Taylor, 1994: Seasonal variations between sampling and classical mean turbulent heat flux estimates in the North Atlantic. Annal.Geophys., In press.

Kent, E.C., R.J. Tiddy, and P.K. Taylor, 1993: Correction of marine air temperature observations for solar radiation effects. J.Atmos.Oceanic.Technol., 10, 900-906.

Kent, E. C. and P.K. Taylor, 1995: A comparison of heat flux estimates for the North Atlantic ocean. J. Phys. Oceanogr. 25, 1530-1549.

Lambert, S.J. and G.J. Boer, 1989: Atmosphere-ocean heat fluxes and stresses in general circulation models. Atm.Ocean., 27, 692-715.

Li, A., H.G. Leighton, K. Masuda and T. Takashima, 1993: Estimation of SW flux absorbed at the surface from the TOA radiative flux, J. Climate, 6, 317-330.

Liu, W.T., 1988: Moisture and latent heat flux variabilities in the tropical Pacific derived from satellite data. J. Geophys. Res., 93, 6749-6760.

Liu, W.T., W. Tang and F.J. Wentz, 1992: Precipitable water and surface humidity over global oceans from special sensor microwave imager and ECMWF forecasts, J. Geophys.Res., 97, 22512264.

Oberhuber, J.,M., 1988: The Budgets of Heat, Buoyancy and Turbulent Kinetic Energy at the Surface of the Global Ocean. Max-Plank-Institute for Meteorology/Hamburg Report No. 15.

Payne, R., 1972: Albedo of the sea surface. J.Atmos.Sci, 29, 960-970.

Randall, D.A. and P.J. Gleckler: Diagnosis of simulated ocean surface heat fluxes and the implied partitioning of meridional heat transport between the atmosphere and ocean. Proceedings of the First International AMIP Conference, May 1995, Monterey, CA, WCRP Rep. In preparation.

Reed, R.K. and R.E. Brainard, 1983: A comparison of computed and observed insolation under clear skies over the Pacific Ocean. J.Appl.Met., 22, 1125-1128.

Reed, R.K., 1982: Comparison of measured and estimated insolation over the eastern Pacific Ocean. J. Appl.Met, 21.339-341 
Reed, R.K., 1977: On estimating insolation over the ocean. J. Phys.Oceanogr., 7, 482-485.

Sarachik, E.S., 1984: Large scale surface heat fluxes. Large-scale oceanographic experiments and satellites. (Eds. C. Gautier and M. Fieux). Dordrecht, Holland: Reidel.

Saur, J.F.T., 1963: A study of the quality of sea water temperature reported in logs of ships weather observations. J.Appl. Meteor, 2, 417-425.

Simonot, J.Y., and H. Le Treut, 1987: Surface heat fluxes from a numerical weather prediction system. Clim.Dyn., 2, 11-28.

Simmonds, I. and M. Dix, 1989: The use of mean atmospheric parameters in the calculation of modeled mean surface heat fluxes over the world's oceans. J. Phys.Oceanogr, 19, 205-215.

Simpson, J.J. and Paulson, C.A., 1979: Mid-ocean observations of atmospheric radiation. Quart. J. Roy. Meter. Soc., 105, 487-502.

Taylor, P.K., E. Kent, M. Yelland and B. Moat, 1994: The accuracy of wind observations from ships. Proceeding for the COADS Winds Workshop, June, 1994.

Taylor, P.K., 1984: The determinations of surface fluxes of heat and water by satellite microwave radiometer and in situ measurments. Large-scale oceanographic experiments and satellites. (Eds. C. Gautier and M. Fieux). Dordrecht, Holland: Reidel.

Taylor, J.R., 1982: An introduction to error analysis. University Science Books, Mill Valley, CA. Trenberth, K. and A. Solomon, 1994: The global heat blance: heat transports in the atmosphere and ocean, Clim.Dyn. 10, 107-134

Warren, S.G., C.J. Hahn, J. London, R.M. Chervin and R.L. Jenne, 1988: Global distribution of total cloud cover and cloud type amounts over the ocean. NCAR Tech. Note TN-317+STR, Boulder, CO 42 pp. +170 maps.

WCRP Report No. 23, 1989: WOCE surface flux determinations - A strategy for in situ measurments. (WMO/TD No. 304).

Weare, B.C., and P.T. Strub, 1981: The significance of sampling biases on calculated monthly means oceanic heat fluxes. Tellus, 33, 211-224.

Weare, B.C., 1989: Uncertainties in estimates of surface heat fluxes derived from marine reports over the tropical and subtropical oceans. Tellus, 41A, 357-370.

Weare, B.C. 1992: Comparisons of multi-year statistics of selected variables from the COADS and the Nimbus-7 and ECMWF data set. Q.J.R. Meteorol.Soc., 118, 965-985. 
Weber, K. H., 1985: On the interdecadal variations of air and sea temperatures over the oceans. Tropical Ocean-Atmos. News, 29, 10-11.

Woodruff, S.D., R.J. Slutz, R.L. Jenne and P.M Streurer, 1987: A comprehensive ocean-atmosphere dataset. Bull.Amer.Meteor.Soc., 68, 1239-1250.

World Meteorological Organization (WMO), 1970: Reports on marine science affaris. Rep. No. 3: The Beaufort scale of wind force. WMO, Geneva, Switzerland, 22pp.

Wright, P.B., 1988: An atlas based on the 'COADS' data set: Fields of mean wind, cloudiness and humidity at the surface of the global ocean. Max-Plank-Institute for Meteorology Report Number 14, Hamburg. 